\title{
Unravelling the Effect of Complexant Number on Remarkably High Static and Dynamic Second Hyperpolarizability of Aziridine Based Diffuse Electron Systems: A Theoretical Study
}

\section{Ria Sinha Roy}

IACS: Indian Association for the Cultivation of Science

Avik Ghosh

Indian Association for the Cultivation of Science

Tamalika Ash

Indian Association for the Cultivation of Science

Soumadip Banerjee

Indian Association for the Cultivation of science

Abhijit Das ( $\square$ spakd@iacs.res.in )

Indian Association for the Cultivation of Science https://orcid.org/0000-0003-3295-0281

\section{Research Article}

Keywords: hyperpolarizability, diffuse electron, non linear optics, complexant

Posted Date: November 9th, 2021

DOI: https://doi.org/10.21203/rs.3.rs-1003297/v1

License: (c) (1) This work is licensed under a Creative Commons Attribution 4.0 International License.

Read Full License 


\title{
Unravelling the effect of complexant number on remarkably high static and dynamic second hyperpolarizability of aziridine based diffuse electron systems: a theoretical study
}

Ria Sinha Roy ${ }^{1}$, Avik Ghosh ${ }^{1}$, Tamalika Ash ${ }^{1}$, Soumadip Banerjee ${ }^{1}$, Abhijit K. Das ${ }^{1 *}$

\author{
Abhijit K. Das \\ * spakd@iacs.res.in \\ 1. School of Mathematical \& Computational Sciences \\ Indian Association for the Cultivation Of Science \\ Kolkata 700032, India.
}




\begin{abstract}
:
Effect of complexant number on second hyperpolarizability of a series of diffuse electron system comprising aziridine (complexant) and alkaline earth metal dopnat (i.e. $\mathrm{Be}, \mathrm{Mg}$ and $\mathrm{Ca}$ ) are explored theoretically. For this, the number of the complexant is increased upto three in a stepwise fashion. Aziridine unit, that is non-covalently linked with dopant, polarizes the ns electron of dopant. This polarizing effect results the higher second hyperpolarizability value of the complexes. . Compared to pristine aziridine moiety, the $\gamma_{\text {avg }}$ of Be-aziridine complex enhances significantly.Interestingly, with increase in the complexant number, the static and dynamic second hyperpolarizability value enhances in monotonical fashion and attains the maximum value when three complexant are employed. Among the studied systems, the shamrock-shaped complex $\left(\mathrm{Ca} @(\text { aziridine })_{3}\right)$ exhibits higher non-linear refractive index as well as remarkably high second hyperpolarizability value $\left(1.83 \times 10^{7}\right.$ a.u. $)$.
\end{abstract}

Key words : hyperpolarizability; diffuse electron; non linear optics; complexant 


\section{Introduction:}

Second hyperpolarizability responsive non-linear materials owing to their versatile range of applications in optical devices[1], ultrafast photonics[2-3] and non-linear optical switching [4] have enthused enormous attention across various disciplines and some of NLO(non-linear optical) responsive materilas have also been commercialized [5].Designing new kind of molecular system with high third order non-linear optical (NLO) coefficient is the subject of extensive research among theoreticians and experimentalists.

Electride, the term coined by Dye[6], are fascinating species in the realm of non-linear optics. They possess anionic vacancies that are occupied by the trapped electrons. Trapped electrons provide magnetic stabilities and have a widespread spectrum of applications in the field of electron emitters,[7]optics,[8] catalysis[9] and so on.The presence of diffuse electrons in electride complexes can considerably enhance the NLO property of the system[10-13]. Finding of stable electride at room temperature[14] and their potential applications have evoked interest in them[15-16]. By far,few strategies[17-20] have been proposed to improve NLO response of the systems and one of the well-known molecular engineering methods is to introduce alkali metal in an organic moiety that eventually serves as complexant. Metal when doped wisely results in the generation of diffuse electrons around it. Doping alkali metal atoms in polyacetylene chains are stated to improve the second hyperpolarizability value significantly[21]. Diffuse electrons are generated when the alkali metal is doped at cage [22], cup [23], chain [24] like complexant.Nanomaterials like graphenes,[25] nanotubes[26]are also utilized as complexant with alkali dopant.The Li atom-doped inorganic electride having basket-shaped complexant, Li@ $\mathrm{B}_{10} \mathrm{H}_{14}$ shows enhanced first hyperpolarizability[27]. These diffuse electrons systems are reported to exhibit higher NLO response. Infact, the usage of larger sized complexants were used to be quite prevalent. Along this line, recently smaller size complexant are also grabbing the attention owing to their flexible shape and binding patterns. The diffuse electrons system with organic complexant $(\mathrm{M}+@$ n6adz $) \mathrm{M}^{\prime-} \quad$ (where $\left.\mathrm{M}, \quad \mathrm{M}^{\prime}=\mathrm{Li}, \quad \mathrm{Na}, \mathrm{K} ; \mathrm{n}=2, \quad 3\right)[28]$, $\mathrm{Li}^{+}\left(\mathrm{NH}_{3}\right)_{4} \mathrm{M}(\mathrm{M}=\mathrm{M}=\mathrm{Li}$, Na, K)[29] (cage shaped) exhibits larger NLO response than the celebrated Li@calix[4]'pyrrole [30] complex having cup-shaped complexant. Interestingly, Jing et al. has noted that use of multiple $\mathrm{NH}_{3}$ as complexant over a single one increases the first 
hyperpolarizability [31], however, there is no such literature studies regarding the effect of complexant number on second hyperpolarizability.Owing to the flexibility of the smaller size complexant $\mathrm{NH}_{3}$, significantly higher first hyperpolarizability of $\mathrm{Li}\left(\mathrm{NH}_{3}\right)_{4} \mathrm{Na}$ complex has been observed compared to the larger size Li@Calix[4]pyrrole-Na complex[31]. This fasicinating result points out that the smaller size complexant are potentially effective in enhancing the NLO responses.So, the choice of asuitable complexant is very important. The shape, size, flexibility and the number of the complexant along with the number of the coordination site available for complexing play a vital role while designing diffuse electron system.

Organic materials due to lesser production cost, high photoelectric coefficients, easy processability [32] are often chosen as potential complexant. Organic material can function both as conjugated [33] and non-conjugated complexing agent [34]. Interestingly, most of the synthesized electrides based on organic systems are non-conjugated, for example azacryptands [35],crown ethers [36] etc. Meant for its flexibility in designing and smaller size,small organic system serves as good complexant and are capable of forming multiple clusters.

Inspired by the aforementioned facts, we have chosen non-conjugated,synthetically available aziridine moiety as a complexing agent for the study. Aziridine, a small three-member heterocyclic ring have nitrogen atom and an acidic proton is attached to the nitrogen. Availability of lone pair on nitrogen makes aziridine a potential candidate as complexant. Experimentalists took a keen interest in aziridine owing to its wide range of pharmaceutical activity[37],utility in the heterocyclic synthesis[38], and so on. Regarding the choice of chemical dopant, the alkaline earth metal are chosen over the alkali metal. In the past few years, there have been exhausting use of alkali dopant $[28,29,24]$ in diffuse electron system and undoubtedly, these systems exhibit enhanced first hyperpolarizability value. However lesser attention has been credited to alkaline earth metal as dopant. There are few complexes, like all metal systems or an inorganic electride like $\mathrm{CuAg} @ \mathrm{Ca} 7 \mathrm{M}(\mathrm{M}=\mathrm{Be}, \mathrm{Mg}$ and $\mathrm{Ca}), \mathrm{M}\left(\mathrm{Ni} @ \mathrm{~Pb}_{12}\right) \mathrm{M}(\mathrm{M}=\mathrm{Be}, \mathrm{Mg}$ and $\mathrm{Ca})$, where alkaline earth metal dopant have been reported[39,40] but, their use as a dopant with the organic complexant, has not been explored much in the literature.On the other hand, literature studies based on second hyperpolarizability responsive organic or organometallic materials are less explored in comparision to first hyperpolarizability responsive complexes. So, herein we aimed to study the effect of aziridine based organometallic systems comprising aziridine molecule (complexant) and alkaline earth metal( $\mathrm{Be}, \mathrm{Mg}$ and $\mathrm{Ca}$ ), on the second hyperpolarizability. 
Since the primary motivation of this work, is to study the effect of complexant number on NLO response, the number of complexants is increased in a very structured pattern and upto three units of complexants(aziridine) are considered. When the complexant number reaches upto three, they form a very symmetric petal like structure particularly with the higher mass dopant like $\mathrm{Mg}$ and $\mathrm{Ca}$. The higher number aziridine cluster might have a intense polarizing effect on dopant and it will be quite interesting to explore the effect of non-conjugating complexant cluster and variation of alkaline earth metal dopant on static and dynamic second hyperpolariozability. We aim to design theoretically a new kind of diffuse electrons system based on alkaline earth metal with high third order NLO coefficient.

\section{Computation details}

Geometry optimizations of the studied molecules have been performed using the Gaussian 09 suite of the quantum chemistry program by employing B3LYP[41] (a hybrid CGA type DFT functional ,comprising of Becke's three parameter exchange functional along with Lee, Yang and Parr (LYP) correlation functional) functional in conjunction with 6-311++G(d,p) basis set. Vibrational frequencies are calculated using the optimized structuresis found to be real for each vibrational mode. The B3LYP optimized structure of the aziridrine molecule agrees well with the experimental data available (proton affinity PA $=905.5$ and gas-phase basicity $=872.5 \mathrm{~kJ} \mathrm{~mol}^{-1}$ ) $[42,43]$ and this functional has also been widely used for optimizing nitrogen based heterocycles[44] and aziridrine based complexes[45].

The binding energy $\left(\Delta \mathrm{E}_{\mathrm{b}}\right)$ is calculated at B3LYP/6-311++G(d,p) level using the following equations $1[12,10]$ at the isolated gas phase,

$\Delta \mathrm{E}_{\mathrm{b}}=\left[\mathrm{E}(\mathrm{M} @ \text { aziridrine })_{\mathrm{n}}-\mathrm{E}(\text { aziridine })_{\mathrm{n}}-\mathrm{E}(\mathrm{M})\right]$

Where $\mathrm{n}=1,2,3$ and $\mathrm{M}=\mathrm{Be}, \mathrm{Mg}$ and $\mathrm{Ca}$.In the above equation the basis set superposition error (BSSE) for the binding energy value is subsequently rectified by employing the Counterpoise method[46].

The vertical ionization energies (VIE) are calculated using the following equation

$$
\mathrm{VIE}=E\left[\mathrm{X}^{+}\right]-E[\mathrm{X}]
$$


where $E[X]$ is the energy of the neutral complex and $E\left[X^{+}\right]$is the energy of the cationic complex.

To have an idea about the accumulation of charge on the atom, natural population analysis (NPA) [47] are carried out at B3LYP/6-311++G(d,p) level. To understand the nature of interaction between $\mathrm{M}$ and aziridine,topological analysis of the atoms i.e. AIM (atoms in molecule) are done employing the AIMALL(atoms in molecule) software[48].This is considered one of the efficient tools to understand the nature of interaction between atoms. The bond critical point (BCP) associated with $(3,-1)$ critical point indicates the nature of the interaction between the two concerned atoms. When $\rho_{(\mathrm{rc})}$ (electron density) for the respective BCP is relatively smaller in magnitude along with its corresponding Laplacian of the electron density is $\nabla_{\rho(\mathrm{rc})}^{2}>0$, this results in depletion of electron density between the concerned atoms. The depletion of electron density indicates that the non-covalent interaction exists between the concerned atoms.Under the influence of strong electric field, the NLO properties of the systems are prevailed. Using the equilibrium structures, the isotropic polarizability and average second hyperpolarizability calculations are performed. The isoptropic polarizability can be expressed by the equation

$\alpha=\left(\alpha_{\mathrm{xx}}+\alpha_{\mathrm{yy}}+\alpha_{\mathrm{zz}}\right) / 3$

The mean second hyperpolarizability $\left(\gamma_{\text {avg }}\right.$ or $\left.\gamma_{\|}\right)$is defined as equation below[49]

$\gamma_{\mathrm{P}}=\frac{1}{15} \sum_{i j=x, y, z}\left[\gamma_{i i j j}+\gamma_{i j j i}+\gamma_{i j i j}\right]$

Choice of DFT functional is crucial for evaluating the isotropic polarizability and second hyperpolarizability. For the long-range interaction, hybrid DFT functional CAM-B3LYP (Coulomb-attenuated hybrid exchange density)[50] has been developed and employed successfully for calculating the second hyperpolarizability of the organometallic complexesand alkaline earth metal-doped complexes $[51,52,10]$. The CAM-B3LYP functional has also been extensively used for evaluating the hyperpolarizability of the electride complexes [53,10]. wB97XD [54] functional that incorporates empirical dispersion correction along with the longrange effects has been successfully employed for calculating the hyperpolarizability of the electride species $[10,12]$. Another hybrid functional, BHandHLYP has been widely used also for 
evaluating the hyperpolarizability of the diffuse electron molecules[10]. Champagne et al.[55] reported that this functional can minimize the higher and overestimated results of hyperpolarizability. However, Nakano et al. [56] have reported that this hybrid functional is able to reproduce the hyperpolarizability values obtained from computationally costly $\operatorname{CCSD}(\mathrm{T})$ method. So, the BHandHLYP functional is quite a decent choice for the theoretical researcher as for larger systems $\operatorname{CCSD}(\mathrm{T})$ is time consuming and computationally expensive for evaluating the second hyperpolarizability. Regarding the basis set, the polarization consistent group of basis sets of Jensen,the aug-pc2[57] is considered for this work (this basis set is augmented with diffuse functions) for evaluating the isotropic polarizability as well as the non-linear hyperpolarizability. Due to the presence of extra diffuse set of function, this basis set has been extensively used for evaluating the hyperpolarizability [58]. Along with it, the 6$311++\mathrm{G}(3 \mathrm{df}, 3 \mathrm{pd})$ and $6-311++\mathrm{G}(\mathrm{d}, \mathrm{p})$ basis set have been employed for all the chosen DFT functionals.Here, we have computed frequency-dependent second hyperpolarizability, the electro-optic Kerr effect $(\gamma(-\omega ; \omega, 0,0))$ and the electric-field induced second harmonic generation $(\mathrm{ESHG})(\gamma(-2 \omega ; \omega, \omega, 0))$ using different frequencies, $\omega=0.001-0.004$ and evaluated the change in non-linear refractive index with the change of frequency. All calculations have been done using Gaussian 09 [59]. The ELF plot are performed by using Multiwfn program package [60].

\section{Results and Discussion}

\subsection{Equilibrium Geometries}

Optimized molecular structures are shown in Fig. 1 and geometrical parameters are enlisted in table 1. In the present study,each aziridine unit is treated as single petal (Fig 1) that functions as complexent. While designing complexes, we have taken care of two aspects, a) to increase the number of petals in a step wise manner((aziridine $\left.)_{1} \rightarrow(\text { aziridine })_{3}\right)$ upto three and $b$ ) variying the alkaline dopant $\mathrm{M}(=\mathrm{Be}(\mathrm{na}), \mathrm{Mg}(\mathrm{nb})$ and $\mathrm{Ca}(\mathrm{nc}))$ of the complexant systematically.So, for the better comprehension, depending upon the petal-number the complexes are categorized into three schemes,i.e.: Scheme I, II and III encompassing one, two and three petals respectively. Among the studied complexes, the aesthetically eye-catching symmetric structure of IIIc complex is quite intriguing. Complex IIIc mimics the shamrock-like shape encompassing the three-lobed petal and the $\mathrm{Ca}$ dopant connects all three of them. Three $\mathrm{N}$ atoms are aligned in triangular array where each $\mathrm{N}$ atom sits at each corner of acute triangle and interestingly with $\mathrm{Ca}$ atom, any two 
of the nitrogen forms a right angled triangle. Lets delve into the key bond distance of the studied complexes, the monotonic rise of $\mathrm{M}-\mathrm{N}$ distance is observed on going from $\mathrm{na} \rightarrow \mathrm{nb} \rightarrow \mathrm{nc}$ for M@aziridine complexes, whereas N-H distance of aziridine is observed to be decreased by $0.02 \AA$. The smallest distance between Be-N (for complex Ia), also indicates the strong binding interation between the aziridine and Be. However, this monotonic rise of $\mathrm{Be}-\mathrm{N}$ is not demonstrated when petal number is more than one. Owing to the smaller size of Be atom,the distance of Be from two aziridine moieties are not found to be same(table 1). For,dopant with higher mass number $\mathrm{Mg}$ and $\mathrm{Ca}(\mathrm{Scheme} \mathrm{II} \rightarrow \mathrm{III})$, the of $\mathrm{N}-\mathrm{H}$ length elongates monotonically i.e., $\mathrm{N}-\mathrm{H}$ of $\mathrm{IIb} / \mathrm{c}<\mathrm{IIIb} / \mathrm{c}$. Investigating the bond angle, the < $\mathrm{CNC}$ bond angle of $\mathrm{Mg}$ complexes exhibit relatively higher value than its $\mathrm{Be} / \mathrm{Ca}$ analogues. On the other hand, change in the binding energy $\Delta \mathrm{E}_{\mathrm{b}}$ of complexant (table 2), with respect to petal number is presented the Fig $\mathrm{S} 1$. Monotonical upturn of $\Delta \mathrm{E}_{\mathrm{b}}$ values is observed with the rise in the number of N-binding sites. Presence of three petals in the scheme III complexes eventualy results in largest binding energy compared to scheme I/II. This in turn envisages better charge transfer interactionin scheme III complexes compared to scheme I/II complexes. The order of enhancement of $\Delta \mathrm{E}_{\mathrm{b}}$ value is: $\mathrm{In}<$ IIn $<$ IIIn $(\mathrm{n}=\mathrm{a} / \mathrm{b} / \mathrm{c})$ like Ia $<$ IIa $<$ IIIa. Shamrock complex IIIc has the highest $\Delta \mathrm{E}_{\mathrm{b}}$ value $(-91.1$ $\mathrm{kJ} / \mathrm{mole}$ ).For scheme I and III, the $\Delta \mathrm{E}_{\mathrm{b}}$ follows an identicalvariationpattern, i.e.nb <na< nc, however for scheme II, the binding energy of IIa is found to be highest.In a given scheme, the lowest binding energy $\Delta \mathrm{E}_{\mathrm{b}}$ is observed when $\mathrm{M}=\mathrm{Mg}($ Fig. S1).Now, it will be interesting to elucide the naure of interaction between $\mathrm{M}$ and complexant and for this the AIM study is carried out.The calculated results are presented in table 3. For the studied complexes, the smaller value of $\rho(\mathrm{rc})$ and positive $\nabla^{2} \rho(\mathrm{rc})$ between $N$ and $M$ for all the three schemes indicate that noncovalent interaction exists between complexant and $\mathrm{M}$.

\subsubsection{Vertical Ionization Energies (VIE).}

The (VIE) of the complexes are calculated employing the equation 2 and the results are collected in table 4.The value of ionization energyof $M$ calculated at B3YP/6-311++G(d,p) level agrees closely with the experimental value[61]. It is observed that the calculated VIE of each of the studied complexes is smaller than the ionization energy of the $M$ that is doped to it. Having a lesser value of VIE of the complex compared to the isolated alkaline earth metal doped to it, is 
one of the important characteristic features of diffuse electron system[10]. The lowest VIE for a given scheme is observed for $\mathrm{Ca}$ complexes. It should also be noted that the VIE follows a diminished trend with the increase in the number of petals.Complexes of Scheme III are reported to have the lowest VIE compared to Scheme I / II.

\subsection{Diffuse electron and charge transfer}

To inspect the presence of diffuse electron character of the studied system, the NPA calculations are carried out and calculated natural charges arecollected in Table 5. In this segment, in the first part, we will address on natural charge of nitrogen atom of complexant unit as it is the key binding site towards dopant and in the later part, the focus will be on natural charge on alkaline earth metal dopant (M).

Nitrogen atom of pristine aziridine moiety exhibits negative charge (-0.633). Compared to the prinstine azidrine, the negative charge on nitrogen atom of aziridine is amplified ( ranging from 0.718 to -0.865$)$ upon complexation with $\mathrm{M}(\mathrm{Be}, \mathrm{Mg}$ and $\mathrm{Ca})$. Now, the more negatively charged nitrogen atom polarizes the alkaline earth metal dopant and eventually pushes away the ns electron of $\mathrm{M}$ atom. The pushing effect caused by the aziridine moiety results in the induced polarization of electron of alkaline earth metal which in turn consequences in the generation of diffuse electron cloud. HOMO surface plot of the molecules (Fig 2. Fig. S2) of scheme I-III shows that the diffuse electron cloud enwraps around the alkaline earth metal and the surface plot is one of the significant features of diffuse electron systems[23,10,12]. Let us , now address the natural charge on dopant, the charge accumulation on $\mathrm{M}$ can be attributed to the distance between the $\mathrm{N}$ atom of complexant and diffuse electron center $\mathrm{Be}$ atom when placed amidst the aziridine petals acquires negative charge while $\mathrm{Mg}$ and $\mathrm{Ca}$ acquires small positive charge.As, it is well known and even from table 1, it is observed that $\mathrm{N}-\mathrm{Mg} / \mathrm{Ca}$ distance is larger compared to $\mathrm{N}-\mathrm{Be}$ distance. As the distance from diffuse electron center to the polarizing unit diminishes, negative charge accumulation is observed on diffuse electron generating center. The negative charge on Be also ratify the fact. Negative charge accumulation on Be compared to another dopants can also be related to higher electron affinity of the former. Interstingly, when dopant is $\mathrm{Mg}$, the $\mathrm{N}-\mathrm{Mg}$ distance is found to be reduced with rise in petal number. Thus, $\mathrm{Mg}$ becomes less positive with higher petal number and with three petals complex, i.e. molecule IIIb, the Mg even 
acquires negative charge. However, maximum positive charge accumulation on $\mathrm{Ca}$ is observed for IIIc.

ELF plot can be essential tool to understand the electronic structure as it can show intuitively degree of localization of electrons for several position. The ELF plot( Fig. 3, S3) for the studied molecules also shows that electron transfer happens from aziridine moiety to metal. The graphical plot(see Fig. S3) also exhibits how the pattern of electron localization changes upon increase in complexant number.

\subsection{Polarizability and Second Hyperpolarizability}

\subsubsection{Effect of Basis set and DFT functional:}

Isotropic polarizabilities of the studied complexes are listed in tables S1 (supplementary section). Basis set and functional play important role in evaluating the polarizability as well as hyperpolarizability value. Considering, the basis set effect, the isotropic polarizability calculated with the polarization consistent basis set having additional diffuse function (aug) aug-pc2 and higher polarization function consisting basis set $6-311++\mathrm{G}(3 \mathrm{df}, 3 \mathrm{pd})$ basis set have marginally higher value compared to $6-311++\mathrm{G}(\mathrm{d}, \mathrm{p})$ basis set. Regarding functional, the calculated $\alpha_{0}$ values for Ia, Ib, IIa, IIIa at wB97XD and CAM-B3LYP levels are fairly close to each other at 6-311++G(d,p)/6-311++G(3df,3pd)/aug-pc2 basis set. For molecule IIb, the evaluated $\alpha_{0}$ value of BHandHLYP agrees almost with the value calculated by wB97XD method. However, for rest of the molecules, the CAM-B3LYP calculated isotropic polarizability value matches with the BHandHLYP results. The calculated static second hyperpolarizability value (Table 6,S2 (supplymentary section)) for all the chosen methods gives identical variation of second hyperpolarizability in a given scheme also when compared in between the schemes.Let us consider the effect of functional on the value of second hyperpolarizability (table 6). CAMB3LYP and BHandHLYP calculated second hyperpolarizability values for Ia, IIa IIc values matches closely with each other. However, for molecules Ib, Ic, IIIa and IIIc, the values

calculated by CAM-B3LYP method agree within narrow margin with the results obtained by wB97XD method. wB97XD results for molecule IIb, IIc and IIIb values are underestimated compared to BHandHLYP and CAM-B3LYP results. The calculated second hyperpolarizability 
value at aug-pc2 basis set is reported to be higher compared to values reported at 6$311++\mathrm{G}(3 \mathrm{df}, 3 \mathrm{pd})$ and $6-311++\mathrm{G}(\mathrm{d}, \mathrm{p})$ basis sets. The presence of diffuse function plays vital role while evaluating the NLO responses. The augpc-2 basis set is important in evaluating the $\gamma_{\mathrm{avg}}$ value. To check the effect of higher polarization function compared to $6-311++G(d, p)$, the 6$311++\mathrm{G}(3 \mathrm{df}, 3 \mathrm{pd})$ basis set has been chosen. All the chosen basis sets are extensively used in evaluating the NLO properties.

\subsubsection{Variation of polarizability and second hyperpolarizability.}

All the complexes shows considerably high value of polarizability.Interesingly, it can be noted that the isotropic polarizability increases with increase in petal number, of the complexes; for example, Ia $<$ IIa $<$ IIIa, (Fig. S4) and so on.

For static $\gamma_{\text {avg, }}$, we have divided our discussion in two segments. In the first part, we will focus on impact of $\mathrm{M}$ dopant on hyperpolarizability of the complexes while in the second part, we will address on effect of the number of petal on second hyperpolarizability. Before discussing the effect of number of petal or size of $\mathrm{M}$ on $\gamma_{\mathrm{avg}}$, it is worthy to discuss how the presence of $\mathrm{M}$ atom affects the $\gamma_{\text {avg }}$ of the aziridine complex. For this, we have calculated the $\gamma_{\text {avg }}$ of pristine aziridine and the calculated value is $5.21 \times 10^{3}$ au ((CAM-B3LYP/6-311++G(d,p)). Upon complexation with smallest alkaline earth metal Be, the value of $\gamma_{\text {avg }}$ increases by about 54 times. The presence of diffuse electron in Ia is responsible for the many fold increase of $\gamma_{\text {avg }}$ value. The higher $\gamma_{\text {avg }}$ of the complexes when $\mathrm{M}=\mathrm{Ca}$ for every scheme.

Now, let us focus on dependence of NLO property on the number of complexant. The generation of the diffuse electrons cloud primarily depends on the polarizing unit. As the number of polarizing unit or petal increases, the polarizing power of the overall moiety also increases. This higher polarizing power of the overall complexant results in the higher $\gamma_{\text {avg }}$ of the diffuse electron systems of Scheme III compared to schemes II and I. The variation of $\gamma_{\mathrm{zzzz}}$ and $\gamma_{\mathrm{avg}}$ follow the succeeding trend (Petal number one: $\operatorname{In}(n=a / b / c)<$ two $: \operatorname{IIn}(n=a / b / c)<$ three: $\operatorname{IIIn}(a / b / c)$, i.e., Ia < IIa < IIIa. Complex IIIc which has highest binding energy also reported to have highest $\gamma_{\text {avg }}$ value among the studied complexes. The graph in Fig.3, visibly points out that with increasing the petal number, the $\gamma_{\text {avg }}$ can also be enhanced. This can be regarded as an interestingly finding that the altering the complexant number, the static $\gamma_{\text {avg }}$ can also be tuned. Interesingly, both $\alpha$ and 
static $\gamma_{\text {avg }}$ exhibit identical pattern of enhancement with respect to increase in petal number. Complex of Scheme III also reported to have lowest VIE .

Moreover, in order to check how the variation of frequency plays important part in NLO responses of investigated systems, we have evaluated the frequency dependent third order polarizability and the results are collected in table 7.The induced dipole moment of the molecule varies as a result of interaction with the external radiation and along with it, the second hyperpolarizability also changes. So, the different external frequencies (0.001-0.004) are used to compute the coefficients of second hyperpolarizability.From the computed value, it can be noted that the value of the second hyperpolarizability(the dc-Kerr effect) $\gamma(-\omega ; \omega, 0,0)$ and the (ESHG) effect which is denoted by $\gamma(-2 \omega ; \omega, \omega, 0)$ increases compared to static field. So, the frequency dependent value of second hyperpolaizability is higher compared to static one. Tarazkar et al. [62] have calculated the degenerate four-wave mixing (DFWM) values with the help of ESHG,dc-Kerr and static second hyperpolarizability coefficients from the eq. (5)

$\gamma_{\text {DFWM }}(-\omega ; \omega,-\omega, \omega) \approx \frac{1}{3} \gamma(-2 \omega ; \omega, \omega, 0)+\gamma(-\omega ; \omega, 0,0)-\left(\frac{1}{3}\right) \gamma(0 ; 0,0,0)$

Using the four wave mixing value of the second hyperpolarizability, the quadratic NLO refractive index [63] can be calculated with the help of equation (6)

$\mathrm{n}_{1}=8.28 \times 10^{-23} \gamma_{\operatorname{DFWM}}(6)$

The calculated non-linear refractive index $\left(\mathrm{n}_{1}\right.$ in au) values are listed in table 7 . It can be noted from table 7 that for all the studied complexes, with the increase in the frequency, the value of $\mathrm{n}_{1}$ decreases. Now, with increasing the number of complexant from one to two, the non- linear refractive index decreases for $\mathrm{Be}$ and $\mathrm{Mg}$ and interestingly, complexes with two complexants show lowest refractive index for those complexes. For Be complexes, the highest value of $\mathrm{n}_{1}$ is observed for Scheme I. However, for Ca complexes, $\mathrm{n}_{1}$ increases with petal number (Ic: 9.2376 $\mathrm{x} 10^{-17} \rightarrow$ IIIc: $1.3962 \times 10^{-15}$ ). Analysing the effect of complexant number on nonlinear refractive index, it can be noted that significant increase in $\mathrm{n}_{1}$ is observed for $\mathrm{Mg} / \mathrm{Ca}$ dopant when complexant number is three(Ib: $2.0908 \times 10^{-17} \rightarrow$ IIIb: $\left.4.0144 \times 10^{-16}\right) /\left(\right.$ Ic: $9.23059 \times 10^{-17} \rightarrow$ IIIc: 1.39318 $\left.\mathrm{x} 10^{-15}\right)$. Maximum value of $\mathrm{n}_{1}$ is observed for IIIc. Refractive index which is the function of 
wavelength also varies with the calculated second hyperpolarizability value and eventually displays the maximum value for the IIIc which exhibits the highest $\gamma_{\text {avg }}$ value.

The spectroscopic parameters calculated bythe time dependent DFT are collected in table 8. The CAM-B3LYP functional has been chosen for the study of spectroscopic property of 30 low lying states. This above functional has been widely used for evaluating the electronic property of diffuse electron systems.[64,10,58]

The TD-DFT calculations of aziridine derivatives are also carried out using the aforementioned functional[45].The variation of static second hyperpolarizability along zzzz axis can be explained by the spectroscopic parameter using thetwo state model [65].

$\gamma_{z z z z}=24\left[\frac{\mu_{n g}^{2} \Delta \mu^{2}}{\Delta E_{e g}^{3}}-\frac{\mu_{n g}^{4}}{\Delta E_{e g}^{3}}\right]$

$\gamma_{z z z z}=18\left[2 \frac{\Delta \mu_{n g}^{2} f}{\Delta E_{n g}^{4}}-3 \frac{f^{2}}{\Delta E_{n g}^{5}}\right]$

$\gamma_{z z z z}=\left[\frac{\mu_{n g}^{4}}{\Delta E_{n g}^{3}}\right] \approx\left[\frac{f^{2}}{\Delta E_{n g}^{5}}\right]$

where $\Delta \mathrm{E}_{\mathrm{ng}}$ is transition energy between ground $(|\mathrm{g}\rangle)$ to the crucial excited state $(|\mathrm{n}\rangle)$, and $\mu \mathrm{ng}$ transition moment associated with it. The dipole moment difference between ground and excited state is indicated by $\Delta \mu$ and $\mathrm{f}$ is the oscillator strength of the crucial transition state.

From the above equation, it is quite evident that variation of the static second hyperpolarizability is quite sensitive to the change in the transition energy gap between the excited and ground state as it appears with higher power. As seen from the table 8 , on going from Ia $\rightarrow \mathrm{IIa} \rightarrow \mathrm{IIIa}$, there is a decrease in the $\Delta \mathrm{E}_{\mathrm{ng}}$ value, which in turn reflected in the higher second hyperpolarizability of the IIa and IIIa. Same trend is observed for IIIb and IIIc where $\Delta \mathrm{E}$ value is the lowest compared to their $\mathrm{Ib} / \mathrm{IIb}$ and Ic/IIc molecules. Lower $\mu_{\mathrm{ng}}$ value is observed for Scheme II complexes compared to Scheme I; however, the higher power of $\Delta \mathrm{E}$ values dominates while explaining the variation 
of hyeprpolaizability. The shamrock-shaped IIIc shows significantly high value of $\mu_{\mathrm{ng}}$, $\mathrm{f}$ along with very low $\Delta \mathrm{E}$, which transpires the higher second hyperpolarizability of IIIc. The frontier molecular orbital diagram of the studied complexes are depicted in the Fig 5 and S5. For the Be complexes, upon excitation the diffuse electron cloud that is concentrated on $\mathrm{Be}$ in the ground state gets drifted away from the metal. In the excited state for IIa and IIIa, the electrons clouds are observed to be located at the both sides of $\mathrm{Be}$ and along with this, the electron cloud gets partially located on the ring nitrogen. Due to the smaller size of $\mathrm{Be}$, in the excited state the electron density gets partially located on the ring which happens to be more closer to the $\mathrm{Be}$ atom rather than being equally distributed over all the rings. Upon excitation,it is observed that forthe $\mathrm{Mg}$ and $\mathrm{Ca}$ complexes, the diffuse electron cloud gets drifted away completely from the dopant andtwo distinct electron density lobes are located at both sides of dopant only. This drifting away effect of electron cloud from the diffuse electron generation centre in the excited state is a characterstic feature of electride complexes.

\section{Conclusion}

In this work, a series of complexes of alkaline earth doped aziridine based system has been theoretically designed and considered further for the study of electronic structure and non-linear response property. AIM analysis indicates the presence of non-covalent interaction between aziridine unit and alkaline earth metal. Nitrogen atom of complexant polarizes the electron of alkaline earth metal leading to the generation of diffuse electron wrapping the metal. From the HOMO surface plot, it can be seen that the distended electron cloud forms around the M results in the enhancement of the average second hyperpolarizability value of the complex significantly. Compared to pristine aziridine moiety, the $\gamma_{\text {avg }}$ of Be-aziridine complex (Ia) enhances around 54 times. By varying the dopant, maximum NLO responses have been observed when $\mathrm{M}$ is $\mathrm{Ca}$. It is observed that the $\gamma_{\text {avg }}$ value increases with increasing number of complexant in monotonic fashion. Maximum $\gamma_{\text {avg }}$ value is exhibited for the complexes of Scheme III, where three complexants are employed. The ESHG and dc-Kerr coefficient of $\gamma$ are found to be higher compared to the static second hyperpolarizability. It is important to note here that non-linear refractive index varies with changing of frequency and with the increase in frequency, the $\mathrm{n}_{1}$ decreases. Shamrock-shaped IIIc shows both highest linear refractive index value and highest 
average second hyperpolarizability value. Henceforth, the present study envisions new prospective in designing a novel kind of diffuse electron system which is based on small, flexible, synthetically available, non conjugated organic complexant aziridine and the newly designed organometallic complexes can potentially serve as highly responsive third order optoelectronic NLO material.

\section{Acknowlegment:}

RSR acknowledges CSIR(file number: 09/080(1150)/2020-EMR-I) for the fellowship support.Authors are also thankful to Tanay Debnath for his support.

\section{Author's contribution}

All authors contributed to the present work by giving their own conception and design. The computational tasks, tabulation of results, and appropriate theoretical justification/analysis were performed by Ria Sinha Roy, Avik Ghosh, Tamalika Ash, Soumadip Banerjee. The manuscript in the final form was checked and prepared by Ria Sinha Roy and Abhijit K. Das. All authors gave their specific scientific inputs and suggestions to improve the quality of the manuscript. All authors read and approved the final manuscript.

Data availability N/A

Code availability N/A

Declarations

Ethics approval and consent to participate N/A

Consent for publication N/A

Conflict of interest The authors declare that they have no conflict of interest.

\section{References}

1 (a) Bennion I, Goodwin MJ (1993) Third-order nonlinear guided-wave optical devices. In:R.W. Eason,A. Miller (eds) Nonlinear Optics in Signal Processing. Engineering Aspects of Lasers Series, 49. Springer, Dordrecht (b) J. Zyss, Molecular Nonlinear Optics: Materials, Physics and Device, Academic Press, New York, 1994

2 Maidur SR, Patil PS , Katturi NK,Soma VR, Wong QA, Quah CK (2021) Ultrafast Nonlinear Optical and Structure-Property Relationship Studies of Pyridine-Based Anthracene Chalcones Using ZScan,Degenerate Four-Wave Mixing and Computational Approaches. J Phys Chem B 125(15) :38833898.

3. Chu S, Wang S, Gong Q (2012) Ultrafast third-order nonlinear optical properties of graphene in aqueous solution and polyvinyl alcohol film. Chem Phys Lett 523: 104-106. 
4.Gauthier N, Argouarch G, Paul F, Toupet L, Ladjarafi A,Costuas K, Halet JF,Samoc M,Cifuentes MP,Corkery TC, Humphrey MG (2011) Electron-Rich Iron/Ruthenium Arylalkynyl Complexes for Third-Order Nonlinear Optics: Redox-Switching between Three States.Chem - Eur J 17: 5561-5577.

5. Kanis DR,Ratner MA,Marks TJ (1994) Design and construction of molecular assemblies with large second-order optical nonlinearities, Quantum chemical aspects.Chem Rev 9(1): 195-242.

6 Dye JL (1990) Ionic Salts with Electrons as the Anions.Science 247 (4943): 663-668.

7 Huang RH,Dye JL (1990) Low temperature $\left(-80^{\circ} \mathrm{C}\right)$ thermionic electron emission from alkalides andelectrides. Chem Phys Lett 166:133-136.

8 He H-M, Li Y, Yang H,Yu D,Li S-Y,Wu D,Hou J-H,Zhong R-L,Zhou Z-J,Gu F-L,LuisJM,Li Z-R (2017)Efficient External Electric Field Manipulated Nonlinear Optical Switches ofAll-Metal Electride Molecules with Infrared Transparency: Nonbonding Electron Transfer Forms an Excess Electron Lone Pair. J Phys Chem C 121: 958-968.

9 (a)Ye T-N,Li J,Kitano M,Hosono $\mathrm{H}$ (2017)Unique nanocages of $12 \mathrm{CaO} \cdot 7 \mathrm{Al}_{2} \mathrm{O}_{3}$ boost heterolytic hydrogen activation and selective hydrogenation of heteroarenes over ruthenium catalyst.Green Chem19:749-756. (b)Toda Y, Hirayama H, Kuganathan N,Torrisi A, Sushko PV,Hosono H (2013) Activation and Splitting of Carbon Dioxide on the Surface of an Inorganic Electride Material.Nat Commun 4:2378.

10 Roy RS,Nandi PK (2018) Electronic structure and large secondorder non-linear optical property of COT derivatives - a theoretical exploration. Phys Chem Chem Phys 20: 18744-18755

11 Sun W-M,Li X-H,Wu J ,Lan J-M,Li C-Y, Wu D, Li Y,Li Z-R (2017) Can Coinage Metal Atoms Be Capable of Serving as an Excess Electron Source of Alkalides with Considerable Nonlinear Optical Responses? Inorg Chem 56: 4594-4600 .

12 Roy RS, Ghosh S, Hatua K, Nandi PK (2021)Superalkali-doped borazine and lithiated borazine complexes: diffuse excess electron and large first-hyperpolarizability. J Mol Model 27: 74.

13 Li Z-J, Wang F-F, Li Z-R, Xu H-L,Huang X-R,Wu D, Chen W, Yu G-T, Guz FL, Aoki Y(2009) Large static first and second hyperpolarizabilities dominated by excess electron transition for radical ion pair salts $\mathrm{M}_{2}+\mathrm{TCNQ}+$. $(\mathrm{M}=\mathrm{Li}, \mathrm{Na}, \mathrm{K})$. Phys Chem Chem Phys 11: 402-408.

14 Matsuishi S, Toda Y,Miyakawa M,Hayashi K, Kamiya T, Hirano M, Tanaka I, Hosono H(2003) High-Density Electron Anions in a Nanoporous Single Crystal: $\left[\mathrm{Ca}_{24} \mathrm{Al}_{28} \mathrm{O}_{64}\right]^{4+}(4 \mathrm{e}-)$. Science 301: 626629.

15 Kim SW,Toda Y,Hayashi K,Hirano M,Hosono H (2006)Synthesis of a Room Temperature Stable $12 \mathrm{CaO} \cdot 7 \mathrm{Al}_{2} \mathrm{O}_{3}$ Electride from the Melt and Its Application as an Electron Field Emitter. Chem Mater 18: $1938-1944$.

16 Kitano M,Inoue Y,Yamazaki Y,Hayashi F,Kanbara S,Matsuishi S,Yokoyama T,Kim SW,Hara M, Hosono H (2012) Ammonia synthesis using a stable electride as an electron donor and reversible hydrogen store. Nat Chem 4: 934-940. 
17 (a) Zhu L, Xue K, Hou J (2019) A theoretical study of alkaline-earthides $\mathrm{Li}\left(\mathrm{NH}_{3}\right)_{4} \mathrm{M}$ (M = Be, Mg, Ca) with large first hyperpolarizability. J Mol Model 25: 150 (a) Chen W, Li ZR., Wu D, Li RY, Sun CC (2005) Theoretical Investigation of the Large Nonlinear Optical Properties of (HCN)n Clusters with Li Atom. J Phys Chem B 109: 601-08.(b) Kuniyil MJK, Padmanaban R (2019) Theoretical insights into the structural, photophysical and nonlinear optical properties of phenoxazin-3-one dyes. New J Chem 43: 13616-13629. (c) Sun W-M, Chen C-Y, Li C-Y, Wu D, Kang J, Li Y, Li Z-R (2018) Boron-Substituted Coronene: Intriguing Geometric and Electronic Properties, and Large Nonlinear Optical Response. chem phys chem 19: 2518-2524 (d) Avramopoulos A, Reis H, Li J, Papadopoulos MG (2004) The Dipole Moment, Polarizabilities, and First Hyperpolarizabilities of HArF. A Computational and Comparative Study. J Am Chem Soc 126 (19) : 6179 -6184. (e) Karamanis P, Pouchan C ( 2013) Second-Hyperpolarizability $(\gamma)$ Enhancement in Metal-Decorated Zigzag Graphene Flakes and Ribbons: The Size Effect. J. Phys. Chem. C 117 (6) : 3134-3140 (f) ) Karamanis P, Pouchan C (2012) Fullerene- $\mathrm{C}_{60}$ in Contact with Alkali Metal Clusters: Prototype Nano-Objects of Enhanced First Hyperpolarizabilities. J Phys Chem C 116( 21) : 11808-11819

18 (a) Sun W-M, Li X-H, Li Y, Ni B-L, Chen J-H , Li C-Y ,Wu D, Li Z.-R (2016) Theoretical Study of the Substituent Effects on the Nonlinear Optical Properties of a Room-Temperature-Stable Organic Electride. chem phys chem 17: 3907-3915 (b) Kulichenko M, Utenyshev AN, Bozhenko KV (2021) Designing Molecular Electrides from Defective Unit Cells of Cubic Alkaline Earth Oxides. J Phys Chem C 125:9564-9570 (c) Hou J, Liu Y, Zhang X, Duan Q, Jiang D, Qin J, Zhao R (2018) Electric-fieldinduced nonlinear optical switches of all-metal spherical aromatic molecules with infrared transparency: a theoretical study. New J Chem 42: 1031-1036 (d) Ishaq M, Shehzad RA, Yaseen M, Iqbal S, Ayub K, Iqbal J (2021) DFT study of superhalogen-doped borophene with enhanced nonlinear optical properties J Mol Model 27: 188

19 (a) Pielak K, Tonnelé C, Sanguinet L, Cariati E, Righetto S, Muccioli L, Castet F, Champagne B (2018) Dynamical Behavior and Second Harmonic Generation Responses in Acido-Triggered Molecular Switches. J Phys Chem C 122(45) : 26160-26168. (b) Castet F, Rodriguez V , Pozzo J-L, Ducasse L, Plaquet A, Champagne B (2013) Design and Characterization of Molecular Nonlinear Optical Switches. Acc Chem Res 46(11) : 2656-2665.(c) Bhattacharyya S, Mukherjee PK, Fricke B (2020) Nonlinear response properties of atomic hydrogen under quantum plasma environment: A time-dependent variation perturbation study on hyperpolarizability and two-photon excitations. Int J Quantum Chem 120: e26422 (d) Shakerzadeh E., M. karbasiyuon (2019) Electro-optical properties of bowl-like B 36 cluster doped with the first row transition metals: A DFT insight. Physica E: Low-dimensional Systems and Nanostructures. 
114: 113599 (e) Shakerzadeh E, Duong LV, Tahmasebi E, Nguyen MT (2019) The scandium doped boron cluster $\mathrm{B}_{27} \mathrm{Sc}_{2}^{+}$: a fruit can-like structure. Phys Chem Chem Phys 21: 8933-8939

20 (a) Marques S, Castro MA, Leão SA, Fonseca TL (2018) Electronic and Vibrational Hyperpolarizabilities of Lithium Substituted (Aza)benzenes and (Aza)naphthalenes. J Phys Chem A 122(37) : 7402-7412.(b) Jin Y, Maroulis G, Kuang X, Ding L, Lu C, Wang J, Lv J , Zhang C, Ju M (2015) Geometries, stabilities and fragmental channels of neutral and charged sulfur clusters: $\mathrm{S}_{\mathrm{n}}{ }^{\mathrm{Q}}(\mathrm{n}=3-$ 20, Q = 0, \pm 1 ). Phys Chem Chem Phys $17: 13590-13597$

21 Champagne B,Spassova M, Jadin JB, Kirtman B (2002) Ab Initio Investigation of Doping-Enhanced Electronic and Vibrational Second Hyperpolarizability of Polyacetylene Chains. J Chem Phys 116 : 3935-3946.

22 Wang JJ, Zhou ZJ, Bai Y, Liu ZB, Li Y, Wu D, Chen W, Li ZR, Sun CC (2012) The Interaction between Superalkalis $\left(\mathrm{M}_{3} \mathrm{O}, \mathrm{M}=\mathrm{Na}, \mathrm{K}\right)$ and a $\mathrm{C}_{20} \mathrm{~F}_{20}$ Cage Forming Superalkali Electride Salt Molecules with Excess Electrons Inside the $\mathrm{C}_{20} \mathrm{~F}_{20}$ Cage: Dramatic Superalkali Effect on the Nonlinear Optical Property.J MaterChem 22: 9652-9657.

23 Chen W,Li ZR,WuD,Li Y,Sun CC,Gu FL,Aoki Y (2006) Nonlinear Optical Properties of Alkalides $\mathrm{Li}+\left(\right.$ calix[4]pyrrole) $\mathrm{M}^{-}(\mathrm{M}=\mathrm{Li}, \mathrm{Na}$, and $\mathrm{K})$ : Alkali Anion Atomic Number Dependence. J Am Chem Soc 128: 1072-1073.

24 Xu HL,Li ZR,Wu D,Wang BQ,Li Y,Gu FL,Aoki Y(2007) Structures and Large NLO Responses of New Electrides: Li-Doped Fluorocarbon Chain. J Am Chem Soc129 : 2967-2970.

25 Zhou ZJ,Liu ZB,Li ZR,Huang XR,Sun CC (2011) Shape Effect of Graphene Quantum Dots on Enhancing Second-Order Nonlinear Optical Response and Spin Multiplicity in $\mathrm{NH}_{2}-\mathrm{GQD}-\mathrm{NO}_{2} \mathrm{Systems}_{\text {. }}$ J Phys Chem C 115 : 16282- 16286

26 Zhong RL, Xu HL, Sun SL, Qiu YQ, Su ZM(2012), The Excess Electron in a Boron Nitride Nanotube: Pyramidal NBO Charge Distribution and Remarkable First Hyperpolarizability. Chem - Eur J18 :11350-11355

27 Muhammad S,Xu HL,Liao Y,Kan YH,Su ZM (2009) Quantum Mechanical Design and Structure of the Li@ $\mathrm{B}_{10} \mathrm{H}_{14}$ Basket with a Remarkably Enhanced Electro-Optical Response.J Am Chem Soc 131 : 11833-11840.

28 Wang FF,Li ZR,Wu D,Wang BQ,Li Y,Li ZJ,Chen W,Yu GT,Gu FL,Aoki Y(2008) Structures and Considerable Static First Hyperpolarizabilities: New Organic Alkalides (M+@n6adz) $\mathrm{M}^{\prime}-\left(\mathrm{M}, \mathrm{M}^{\prime}=\mathrm{Li}\right.$, $\mathrm{Na}, \mathrm{K} ; \mathrm{n}=2,3$ ) with Cation Inside and Anion Outside of the Cage Complexants. J Phys Chem B 112 : 1090-1094.

29 Jing Y-Q, Li Z-R, Wu D, Li Y, Wang B-Q, Gu FL, Aoki Y (2006) Effect of the Complexant Shape on the Large First Hyperpolarizability of Alkalides $\mathrm{Li}+\left(\mathrm{NH}_{3}\right)_{4} \mathrm{M}^{-}$. Chem Phys Chem $7: 1759$ - 1763

30 Chen W, Li ZR, Wu D, Li Y, Sun CC, Gu FL (2005)The Structure and the Large Nonlinear Optical Properties of Li@ Calix[4]pyrrole. J Am Chem Soc 127: 10977-10981 
31 Jing YQ, Li ZR,Wu D, Li Y, Wang BQ,Gu FL (2006) What is the role of the complexant in the large first hyperpolarizability of sodide systems $\mathrm{Li}\left(\mathrm{NH}_{3}\right)_{\mathrm{n}} \mathrm{Na}(\mathrm{n}=1-4)$ ? J Phys Chem B 110 : 11725-11729

33 (a)Wang CH, Ma NN, Sun XX, Sun SL, Qiu YQ, Liu PJ (2012) Modulation of the Second- Order Nonlinear Optical Properties of the Two-Dimensional Pincer Ru(II) Complexes: Substituent Effect and Proton Abstraction Switch. J Phys Chem A 116 : 10496-10506. (b) Zhang MY,Wang CH,Wang WY,Ma NN,Sun SL,Qiu YQ (2013) Strategy for Enhancing Second-Order Nonlinear Optical Properties of the Pt(II) Dithienylethene Complexes: Substituent Effect, $\pi$-Conjugated Influence, and Photoisomerization Switch. J Phys Chem A 117 : 12497-12510.

34 Redko MY, Jackson JE, Huang RH,Dye JL (2005) Design and Synthesis of a Thermally Stable Organic Electride. J Am Chem Soc 127 : 12416-12422.

35 Huang RH, Faber MK ,Moeggenborg KJ, Ward DL,Dye JL (1988) Structure of K+(cryptand[2.2.2J) electride and evidence for trapped electron pairs.Nature331 : 599-601

36 Ellaboudy A, Dye JL, Smith PB (1983) Cesium 18-crown-6 compounds. A crystalline ceside and a crystalline electride. J Am Chem Soc 105 : 6490 - 6491.

37 Singh GS (2016) Synthetic Aziridines in Medicinal Chemistry: A Mini-Review. Mini Rev Med Chem16 :892-904

38 Degennaro L,Trinchera P,Luisi R (2014) Recent Advances in the Stereoselective Synthesis of Aziridines. Chem Rev114: 7881-7929

39 He H-M, Li Y, Yang H, Yu D, Li S-Y, Wu D, Hou J-H, Zhong R-L, Zhou Z-J, Gu F-L, Luis JM, Li Z-R (2017) Efficient External Electric Field Manipulated Nonlinear Optical Switches of All Metal Electride Molecules with Infrared Transparency: Nonbonding Electron Transfer Forms anExcess Electron Lone Pair. J Phys Chem C 121 : 958-968

40 He H-M, Li Y, Sun W-M, Wang J-J, Wu D, Zhong R-L, Zhou Z-J, Li Z-R (2016) All-metal electride molecules $\mathrm{CuAg} @ \mathrm{Ca}_{7} \mathrm{M}(\mathrm{M}=\mathrm{Be}, \mathrm{Mg}$, and $\mathrm{Ca})$ with multi-excess electrons and allmetal polyanions: molecular structures and bonding modes as well as large infrared nonlinear optical responses. Dalton Trans 45: 2656-2665.

41(a) Becke AD (1993)Density-functional thermochemistry III. The role of exact exchange.J Chem Phys 98 : 5648-5652(b) Lee C,Yang W, Parr RG (1988)Development of the Colle-Salvetti correlation-energy formula into a functional of the electron density.Phys Rev B Condens Matter 37 :785-789

42 Hunter EP, Lias SG (1998) Evaluated Gas Phase Basicities and Proton Affinities of Molecules: An Update. J Phys Chem Ref. Data 27 : 413

43 Saeidian H, Barfinejad E, Vessally E (2020) Effect of aromaticity and ring strain on proton affinity of aziridine and amidine skeletons: a DFT study. J Iran Chem Soc 17: 1731-1741. 
44 Patra SG (2019) Basicity of N-heterocyclic carbene and its main-group analogues. Comput Theor Chem $1164: 112557$

45 Khalili G, McCosker PM, Clark T, Keller PA(2019) Synthesis and Density Functional Theory Studies of Azirinyl and Oxiranyl Functionalized Isoindigo and (3Z,3'Z)-3,3'-(ethane-1,2-diylidene)bis(indolin-2one) Derivatives.Molecules 24: 3649

46 (a)Boys SF,Bernardi F (1970) The calculation of small molecular interactions by the differences of separate total energies. Some procedures with reduced errors. Mol Phys19 : 553-566.(b) Hobza P ,Havlas Z (1998) Counterpoise-corrected potential energy surfaces of simple H-bonded systems. Theor Chem Acc 99 : 372-377.

47 Reed AE, Weinstock RB,Weinhold F (1985)Natural population analysis. J Chem Phys 83 :735-746.

48 KeithT (2017) AIMAll (Version 17.01.25); TK Gristmill Software: Overland Park, KS,.

49 (a) Kongsted J,Osted A,Mikkelsen KV,Christiansen O (2004) Second harmonic generation second hyperpolarizability of water calculated using the combined coupled cluster dielectric continuum or different molecular mechanics methods. J Chem Phys 120 : 3787-3798. (b) Muhammad S, Chaudhry AR, Irfan A , Al-Sehemi A G (2017) First-principles study of nitrogen-doped nanographene as an efficient charge transport and nonlinear optical material. RSC Adv $7: 36632-36643$

50 Yanai T,Tew DP, Handy NC (2004)A new hybrid exchange-correlation functional using theCoulomb-attenuating method (CAMB3LYP). Chem Phys Lett 393 :51-57.

51 Srivastava AK(2021)Lithiated Graphene Quantum Dot and its Nonlinear Optical Properties Modulatedby a Single Alkali Atom: A Theoretical Perspective.Inorg Chem 60(5) : 3131-3138.

52 Wang S-J,Li Y, Wang Y-F,Wu D,Li Z-R (2013) Structures and nonlinear optical properties of the endohedral metallofullerene-superhalogen compounds $\mathrm{Li} @ \mathrm{C}_{60}-\mathrm{BX} 4(\mathrm{X}=\mathrm{F}, \mathrm{Cl}, \mathrm{Br})$.Phys Chem Chem Phys $15: 12903-12910$.

53 Sun W-M,Wu D, Li Y, Liu J-Y, He H-M, Li Z-R(2015) A theoretical study on novel alkaline earthbased excess electron compounds: unique alkalides with considerable nonlinear optical responses. Phys Chem Chem Phys 17 : 4524- 4532

54 Chai JD,Gordon MH (2008) Long-range corrected hybrid density functionals with damped atomatomdispersion corrections. Phys Chem Chem Phys 10 : 6615-6620

55 Champagne B., Botek E., Nakano M, Nitta T, Yamaguchi K (2005) Basis set and electron correlation effects on the polarizability and second hyperpolarizability of model open-shell $\pi$-conjugated systems. $\mathrm{J}$ Chem Phys 122 : 114315-114312

56 Nakano M, Kishi R, Nitta T, Kubo T, Nakasuji K, Kamada K, Ohta K, Champagne B, Botek E, Yamaguchi K (2005) Second Hyperpolarizability $(\gamma)$ of Singlet Diradical System: Dependence of $\gamma$ on the Diradical Character. J Phys Chem A 109 : 885-891

57 Jensen F ( 2001) Polarization consistent basis sets: Principles. J Chem Phys 115: 9113-125. 
58 Roy RS, Mondal A, Nandi PK (2017) First hyperpolarizability of cyclooctatetraene modulated by alkali and alkaline earth metals. J Mol Model 23: 93.

59 Frisch MJ, Trucks GW, Schlegel HB, Scuseria GE, Robb MA, Cheeseman JR, Scalmani G, Barone V, Mennucci B, Petersson GA, Nakatsuji H, Caricato M, Li X, Hratchian HP, Izmaylov AF, Bloino J, Zheng G, Sonnenberg JL, Hada M, Ehara M, Toyota K, Fukuda R, Hasegawa J, Ishida M, Nakajima T, Honda Y, Kitao O, Nakai H, Vreven T, Montgomery JA, Peralta Jr JE, Ogliaro F, Bearpark M, Heyd JJ, Brothers E, Kudin KN, Staroverov VN, Kobayashi R, Normand J, Raghavachari K, Rendell A, Burant JC, Iyengar SS, Tomasi J, Cossi M, Rega N, Millam JM, Klene M, Knox JE, Cross JB, Bakken V, Adamo C, Jaramillo J, Gomperts R, Stratmann RE, Yazyev O, Austin AJ, Cammi R, Pomelli C, Ochterski JW, Martin RL, Morokuma K, Zakrzewski VG, VothGA, Salvador P, Dannenberg JJ, Dapprich S, Daniels AD, Farkas Ö, Foresman JB, Ortiz JV, Cioslowski J, Fox DJ (2010) Gaussian 09, Revision D.01. Gaussian, Inc., Wallingford CT

60 Lu T, Chen FW (2012) Multiwfn: A multifunctional wavefunction analyser. J Comput Chem 33 : 580592.

61 (a) Lias SG, Bartmess JE, Liebman JF, Holmes JL, Levin RD, Mallard WG (1988) Gas-Phase Ion and Neutral Thermochemistry. J Phys Chem Ref Data Vol. 17, Suppl. No. 1. (b) Lide DR (2000) CRC Handbook of Chemistry and Physics. CRC Press, Boca Raton, FL.

62 Tarazkar M, Romanov DA, Levis RJ(2014) ,Higher-order nonlinearity of refractive index: The case of argon. J Chem Phys 140: 214316

63 Bree C, Demircan A, Steinmeyer G (2010) Method for Computing the Nonlinear Refractive Index via Keldysh Theory. IEEE J Quantum Electron $46: 433-437$ (b) Ullah F, Ayub K, Mahmood T (2020) Remarkable second and third order nonlinear optical properties of organometallic $\mathrm{C}_{6} \mathrm{Li}_{6}-\mathrm{M}_{3} \mathrm{O}$ electrides. New J Chem 44 : 9822-9829

64 W.-M. Sun,L.-T.Fan,Y.Li,J.-Y.Liu,D.Wu,Z.-R.Li, On the Potential Application of Superalkali Clusters in Designing Novel Alkalides with Large Nonlinear Optical Properties.Inorg. Chem. 2014, 53, 6170-6178.

65 (a)Lee W-H,Cho M,Jeon S-J,Cho BR (2000)Two-Photon Absorption and Second Hyperpolarizability of the Linear QuadrupolarMolecule. J Phys Chem A 104: 11033-11040 (b) Banerjee P, Nandi P K (2018) ydrides, alkalides, and halides of calcium metal chain: electronic structure and NLO property. Struct Chem 29 : 859-870 
Table 1 Important geometrical parameters for the optimized Complexes ${ }^{\mathrm{a}}$

\begin{tabular}{|c|c|c|c|c|c|}
\hline \multicolumn{2}{|c|}{ Scheme I } & \multicolumn{2}{|r|}{ Scheme II } & \multicolumn{2}{|r|}{ Scheme III } \\
\hline \multicolumn{6}{|c|}{ N-M ( $(\AA)$} \\
\hline Ia & 1.771 & IIa & $1.735,3.891$ & IIIa & $1.729,4.650,3.976$ \\
\hline $\mathrm{Ib}$ & 2.536 & $\mathrm{IIb}$ & $2.489,2.489$ & IIIb & $2.400,2.410,2.440$ \\
\hline Ic & 2.539 & IIc & $2.573,2.573$ & IIIIc & $2.523,2.526,2.565$ \\
\hline \multicolumn{6}{|c|}{ N-H (̊̊) } \\
\hline Ia & 1.020 & IIa & $1.041,1.015$ & IIIa & $1.044,1.016,1.016$ \\
\hline $\mathrm{Ib}$ & 1.017 & $\mathrm{IIb}$ & $1.018,1.018$ & IIIb & $1.018,1.019,1.020$ \\
\hline Ic & 1.019 & IIc & $1.019,1.019$ & IIII & $1.022,1.023,1.022$ \\
\hline \multicolumn{6}{|c|}{$<\mathrm{CNC}$} \\
\hline Ia & $59.1^{\circ}$ & IIa & $59.5^{\circ}, 59.9^{\circ}$ & IIIa & $59.5^{\circ}, 59.9^{\circ}, 60.1^{\circ}$ \\
\hline $\mathrm{Ib}$ & $60.0^{\circ}$ & $\mathrm{IIb}$ & $59.8^{\circ}, 59.8^{\circ}$ & $\mathrm{IIIb}$ & $59.7^{\circ}, 59.6^{\circ}, 59.9^{\circ}$ \\
\hline Ic & $59.5^{\circ}$ & IIc & $59.6^{\circ}, 59.6^{\circ}$ & IIIc & $59.6^{\circ}, 59.7^{\circ}, 59.6^{\circ}$ \\
\hline
\end{tabular}

a [Ia=Be@aziridine, Ib=Mg@aziridine, Ic=Ca@aziridine / Scheme II: IIa=Be@(aziridine $)_{2}, \mathrm{Il} b=\mathrm{Mg} @$ (aziridine $)_{2}, \quad \mathrm{IIc}=\mathrm{Ca} @(\text { aziridine })_{2}$ / Scheme III: IIIa=Be@(aziridine) $)_{3}, \quad \mathrm{IIIb}=\mathrm{Mg} @(\text { aziridine })_{3}$, IIIc=Ca@ (aziridine $\left.)_{3}\right]$ 
Table 2 Calculated BSSE corrected binding energy $\Delta \mathrm{E}_{\mathrm{b}}(\mathrm{kJ} / \mathrm{mol})$ for the complexes ${ }^{\mathrm{a}}$ of Scheme I-III

\begin{tabular}{llllll}
\hline & $\Delta \mathrm{E}_{\mathrm{b}}$ & \multicolumn{2}{c}{$\Delta \mathrm{E}_{\mathrm{b}}$} & \multicolumn{2}{c}{$\Delta \mathrm{E}_{\mathrm{b}}$} \\
\hline Ia & -34.6 & IIa & -76.5 & IIIa & -90.3 \\
Ib & -8.9 & IIb & -13.2 & IIIb & -13.5 \\
Ic & -36.9 & IIc & -61.8 & IIIc & -91.1
\end{tabular}

a [ Ia=Be@aziridine , Ib=Mg@ aziridine, Ic=Ca@aziridine / Scheme II: IIa=Be @ (aziridine), $\mathrm{IIb}=\mathrm{Mg} @(\text { aziridine })_{2}, \mathrm{IIc}=\mathrm{Ca} @(\text { aziridine })_{2} / \mathrm{Scheme}$ III: IIIa=Be@ (aziridine) $)_{3}, \mathrm{IIIb}=\mathrm{Mg} @(\text { aziridine })_{3}$, IIIc=Ca@ (aziridine $\left.)_{3}\right]$ 
Table 3. Calculated electron density $\rho(\mathrm{au})$ and Laplacians $\nabla_{\rho}^{2}(\mathrm{au})$ obtained at the BCP of each complex

\begin{tabular}{llll}
\hline Molecules & $\mathrm{BCP}$ & $\rho$ & $\nabla_{\rho}^{2}$ \\
\hline Ia & $\mathrm{Be}_{9}-\mathrm{N}_{3}$ & 0.061 & 0.297 \\
Ib & $\mathrm{Mg}_{9}-\mathrm{N}_{3}$ & 0.019 & 0.054 \\
Ic & $\mathrm{Ca}_{9}-\mathrm{N}_{3}$ & 0.029 & 0.124 \\
IIa & $\mathrm{Be}_{17}-\mathrm{N}_{14}$ & 0.067 & 0.329 \\
IIb & $\mathrm{Mg}_{17-\mathrm{N}_{4}}$ & 0.019 & 0.067 \\
IIc & $\mathrm{Ca}_{17}-\mathrm{N}_{4}$ & 0.027 & 0.114 \\
IIIa & $\mathrm{Be}_{25}-\mathrm{N}_{4}$ & 0.069 & 0.336 \\
IIIb & $\mathrm{Mg}_{25}-\mathrm{N}_{4}$ & 0.022 & 0.096 \\
IIIc & $\mathrm{Ca}_{21}-\mathrm{N}_{4}$ & 0.027 & 0.115 \\
\hline
\end{tabular}

[Ia=Be@aziridine , Ib=Mg@aziridine, Ic=Ca@aziridrine / Scheme II: IIa=Be@ (aziridine), IIb=Mg@ (aziridine $)_{2}, \mathrm{IIc}=\mathrm{Ca} @(\text { aziridine })_{2} /$ Scheme III: IIIa=Be @ (aziridine $)_{3}, \mathrm{IIIb}=\mathrm{Mg} @(\text { aziridine })_{3}$, IIIc=Ca@ (aziridine $\left.)_{3}\right]$

Table 4 The VIE(ev) of the studied complexes ${ }^{\mathrm{a}}$ and the Ionization energy(IE) of alkaline earth metal

\begin{tabular}{|c|c|c|c|c|c|c|c|c|}
\hline \multirow[t]{2}{*}{ molecules } & \multirow[t]{2}{*}{ VIE } & \multirow[t]{2}{*}{ molecules } & \multirow[t]{2}{*}{ VIE } & \multirow[t]{2}{*}{ molecules } & \multirow[t]{2}{*}{ VIE } & & \multicolumn{2}{|c|}{ IE(ionization energy) } \\
\hline & & & & & & & B3LYP & EXPERIMENTAL \\
\hline Ia & 5.7 & III & 5.3 & IIIIa & 5.2 & $\mathrm{Be}$ & 9.11 & 9.32 \\
\hline $\mathrm{Ib}$ & 6.1 & $\mathrm{IIb}$ & 4.9 & IIIb & 3.9 & $\mathrm{Mg}$ & 7.73 & 7.65 \\
\hline Ic & 4.9 & IIc & 4.1 & IIIc & 3.4 & $\mathrm{Ca}$ & 6.15 & 6.11 \\
\hline
\end{tabular}

a. [Ia=Be@ aziridine, Ib=Mg@ aziridine, Ic=Ca@aziridine / Scheme II: IIa=Be@ (aziridine $)_{2}, \mathrm{IIb}=\mathrm{Mg} @$ (aziridine $)_{2}, \mathrm{IIc}=\mathrm{Ca} @(\text { aziridine })_{2} /$ Scheme III: IIIa=Be@ (aziridine $)_{3}, \mathrm{IIIb}=\mathrm{Mg} @(\text { aziridine })_{3}$, IIIc=Ca@ $\left.(\text { aziridine })_{3}\right]$ 
Table 5 NPA calculated charges $(q)$ on atom at B3LYP/6-311++G(d,p)

\begin{tabular}{lllllll}
\hline & & $\mathrm{q}^{\mathrm{M}}$ & & $\mathrm{q}^{\mathrm{M}}$ & & $\mathrm{q}^{\mathrm{M}}$ \\
\hline Ia & $\mathrm{M}=\mathrm{Be}$ & -0.016 & IIa & -0.036 & IIIa & -0.032 \\
Ib & $\mathrm{M}=\mathrm{Mg}$ & 0.001 & IIb & 0.000 & IIIb & -0.013 \\
Ic & $\mathrm{M}=\mathrm{Ca}$ & 0.006 & IIc & 0.026 & IIIc & 0.091 \\
& & & & & & \\
\hline & & $\mathrm{q}^{\mathrm{N}}$ & & $\mathrm{q}^{\mathrm{N}}$ & & $\mathrm{q}^{\mathrm{N}}$ \\
& & & & & & \\
\hline Ia & $\mathrm{M}=\mathrm{Be}$ & -0.865 & IIa & -0.801 & IIIa & -0.756 \\
Ib & $\mathrm{M}=\mathrm{Mg}$ & -0.732 & IIb & -0.723 & IIIb & -0.718 \\
Ic & $\mathrm{M}=\mathrm{Ca}$ & -0.783 & IIc & -0.765 & IIIc & -0.780 \\
& & & & & & \\
\hline
\end{tabular}

a. [Ia= Be@aziridine , Ib=Mg@aziridine, Ic=Ca@aziridine / Scheme II: IIa=Be@(aziridine)2, $\mathrm{IIb}=\mathrm{Mg} @(\text { aziridine })_{2}, \quad \mathrm{IIc}=\mathrm{Ca} @(\text { aziridine })_{2} \quad / \quad$ Scheme $\quad$ III: $\quad$ IIIa=Be@ $(\text { aziridine })_{3}$, $\left.\mathrm{IIIb}=\mathrm{Mg} @(\text { aziridine })_{3}, \mathrm{IIIc}=\mathrm{Ca} @(\text { aziridine })_{3}\right]$ 
Table 6Longitudinal component of static second hyperpolarizability $\left(\gamma_{\mathrm{zzzz}}\right.$, au) and average second

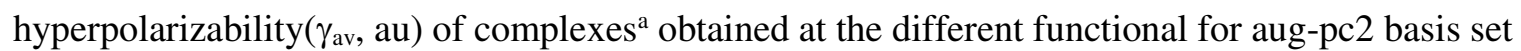

\begin{tabular}{|c|c|c|c|c|}
\hline Molecules & & CAM-B3LYP & BHHLYP & wB97XD \\
\hline \multirow[t]{2}{*}{ Ia } & $\gamma_{\mathrm{av}}$ & $3.13 \times 10^{5}$ & $3.47 \times 10^{5}$ & $3.05 \times 10^{5}$ \\
\hline & $\gamma_{\mathrm{zzzz}}$ & $4.53 \times 10^{5}$ & $5.11 \times 10^{5}$ & $4.35 \times 10^{5}$ \\
\hline \multirow[t]{2}{*}{$1 b$} & $\gamma_{\mathrm{av}}$ & $3.14 \times 10^{5}$ & $3.4 \times 10^{5}$ & $3.19 \times 10^{5}$ \\
\hline & $\gamma_{\mathrm{zzzz}}$ & $3.2 \times 10^{5}$ & $3.52 \times 10^{5}$ & $3.37 \times 10^{5}$ \\
\hline \multirow[t]{2}{*}{$1 \mathrm{c}$} & $\gamma_{\mathrm{av}}$ & $1.88 \times 10^{6}$ & $2.16 \times 10^{6}$ & $1.91 \times 10^{6}$ \\
\hline & $\gamma_{\mathrm{zzzz}}$ & $2.0 \times 10^{6}$ & $2.30 \times 10^{6}$ & $2.11 \times 10^{6}$ \\
\hline \multirow[t]{2}{*}{ IIa } & $\gamma_{\mathrm{av}}$ & $3.58 \times 10^{5}$ & $4.02 \times 10^{5}$ & $2.67 \times 10^{5}$ \\
\hline & $\gamma_{\mathrm{zzzz}}$ & $4.04 \times 10^{5}$ & $4.48 \times 10^{5}$ & $4.12 \times 10^{5}$ \\
\hline \multirow[t]{2}{*}{$\mathrm{IIb}$} & $\gamma_{\mathrm{av}}$ & $1.00 \times 10^{6}$ & $1.23 \times 10^{6}$ & $8.87 \times 10^{5}$ \\
\hline & $\gamma_{\mathrm{zzzz}}$ & $1.06 \times 10^{6}$ & $1.25 \times 10^{6}$ & $1.12 \times 10^{6}$ \\
\hline \multirow[t]{2}{*}{ IIc } & $\gamma_{\mathrm{av}}$ & $5.75 \times 10^{6}$ & $7.14 \times 10^{6}$ & $5.01 \times 10^{6}$ \\
\hline & $\gamma_{\mathrm{zzzz}}$ & $5.70 \times 10^{6}$ & $9.28 \times 10^{6}$ & $5.99 \times 10^{6}$ \\
\hline \multirow[t]{2}{*}{ IIIa } & $\gamma_{\mathrm{av}}$ & $3.47 \times 10^{5}$ & $3.87 \times 10^{5}$ & $3.75 \times 10^{5}$ \\
\hline & $\gamma_{\mathrm{zzzz}}$ & $2.95 \times 10^{5}$ & $3.19 \times 10^{5}$ & $3.12 \times 10^{5}$ \\
\hline \multirow[t]{2}{*}{ IIIb } & $\gamma_{\mathrm{av}}$ & $5.00 \times 10^{6}$ & $7.28 \times 10^{6}$ & $3.36 \times 10^{6}$ \\
\hline & $\gamma_{\mathrm{zzzz}}$ & $1.04 \times 10^{7}$ & $1.58 \times 10^{7}$ & $5.44 \times 10^{6}$ \\
\hline \multirow[t]{2}{*}{ IIIc } & $\gamma_{\mathrm{av}}$ & $1.83 \times 10^{7}$ & $2.34 \times 10^{7}$ & $1.88 \times 10^{7}$ \\
\hline & $\gamma_{\mathrm{zzzz}}$ & $1.66 \times 10^{7}$ & $1.97 \times 10^{7}$ & $1.86 \times 10^{7}$ \\
\hline
\end{tabular}

a. [Ia= Be@aziridine , Ib=Mg@aziridine, Ic=Ca@aziridine / Scheme II: IIa=Be@(aziridine)2, $\mathrm{IIb}=\mathrm{Mg} @(\text { aziridine })_{2}, \quad \mathrm{IIc}=\mathrm{Ca} @(\text { aziridine })_{2} \quad / \quad$ Scheme $\quad$ III: $\quad$ IIIa=Be $@(\text { aziridine })_{3}$, $\left.\mathrm{IIIb}=\mathrm{Mg} @(\text { aziridine })_{3}, \mathrm{IIIc}=\mathrm{Ca} @(\text { aziridine })_{3}\right]$ 
Table 7 Frequency dependent second hyperpolarizability au (dc-kerr $\gamma(-\omega ; \omega, 0,0)$, ESHG $\gamma(-2 \omega ; \omega, \omega, 0)$ )and nonlinear refractive index $\left(\mathrm{n}_{1}\right)$ of studied complex ${ }^{\mathrm{a}}$

\begin{tabular}{|c|c|c|c|c|c|}
\hline & $\omega$ & 0.001 & 0.002 & 0.003 & 0.004 \\
\hline \multirow[t]{3}{*}{ Ia } & dc-Kerr & $293.5 \times 10^{3}$ & $293.7 \times 10^{3}$ & $294.0 \times 10^{3}$ & $294.4 \times 10^{3}$ \\
\hline & ESHG & $293.6 \times 10^{3}$ & $294.1 \times 10^{3}$ & $295.0 \times 10^{3}$ & $296.2 \times 10^{3}$ \\
\hline & $\mathrm{n}_{1}$ & $2.4563 \times 10^{-17}$ & $2.4592 \times 10^{-17}$ & $2.4640 \times 10^{-17}$ & $2.4708 \times 10^{-17}$ \\
\hline \multirow[t]{3}{*}{$\mathrm{Ib}$} & dc-Kerr & $250.2 \times 10^{3}$ & $250.3 \times 10^{3}$ & $250.6 \times 10^{3}$ & $250.9 \times 10^{3}$ \\
\hline & ESHG & $250.3 \times 10^{3}$ & $250.7 \times 10^{3}$ & $251.4 \times 10^{3}$ & $252.3 \times 10^{3}$ \\
\hline & $\mathrm{n}_{1}$ & $2.0908 \times 10^{-17}$ & $2.0929 \times 10^{-17}$ & $2.0966 \times 10^{-17}$ & $2.1017 \times 10^{-17}$ \\
\hline \multirow[t]{3}{*}{ Ic } & dc-Kerr & $110.1 \times 10^{4}$ & $110.2 \times 10^{4}$ & $110.4 \times 10^{4}$ & $110.7 \times 10^{4}$ \\
\hline & ESHG & $110.2 \times 10^{4}$ & $110.5 \times 10^{4}$ & $111.2 \times 10^{4}$ & $112.1 \times 10^{4}$ \\
\hline & $\mathrm{n}_{1}$ & $9.2376 \times 10^{-17}$ & $9.2587 \times 10^{-17}$ & $9.2941 \times 10^{-17}$ & $9.3440 \times 10^{-17}$ \\
\hline \multirow[t]{3}{*}{ IIa } & dc-Kerr & $342.4 \times 10^{3}$ & $342.6 \times 10^{3}$ & $342.9 \times 10^{3}$ & $343.4 \times 10^{3}$ \\
\hline & ESHG & $342.5 \times 10^{3}$ & $343.1 \times 10^{3}$ & $344.1 \times 10^{3}$ & $345.5 \times 10^{3}$ \\
\hline & $\mathrm{n}_{1}$ & $2.8639 \times 10^{-17}$ & $2.8671 \times 10^{-17}$ & $2.8726 \times 10^{-17}$ & $2.8802 \times 10^{-17}$ \\
\hline \multirow[t]{3}{*}{$\mathrm{IIb}$} & dc-Kerr & $958.3 \times 10^{3}$ & $959.2 \times 10^{3}$ & $960.6 \times 10^{3}$ & $962.7 \times 10^{3}$ \\
\hline & ESHG & $958.9 \times 10^{3}$ & $961.5 \times 10^{3}$ & $965.9 \times 10^{3}$ & $972.1 \times 10^{3}$ \\
\hline & $\mathrm{n}_{1}$ & $8.0219 \times 10^{-17}$ & $8.0364 \times 10^{-17}$ & $8.0606 \times 10^{-17}$ & $8.0946 \times 10^{-17}$ \\
\hline \multirow[t]{3}{*}{ IIc } & dc-Kerr & $496.7 \times 10^{4}$ & $497.7 \times 10^{4}$ & $499.4 \times 10^{4}$ & $501.8 \times 10^{4}$ \\
\hline & ESHG & $497.4 \times 10^{4}$ & $500.5 \times 10^{4}$ & $505.6 \times 10^{4}$ & $513.0 \times 10^{4}$ \\
\hline & $\mathrm{n}_{1}$ & $4.1839 \times 10^{-16}$ & $4.2008 \times 10^{-16}$ & $4.2290 \times 10^{-16}$ & $4.2691 \times 10^{-16}$ \\
\hline \multirow[t]{3}{*}{ IIIa } & dc-Kerr & $335.2 \times 10^{3}$ & $335.4 \times 10^{3}$ & $335.7 \times 10^{3}$ & $336.1 \times 10^{3}$ \\
\hline & ESHG & $335.4 \times 10^{3}$ & $335.9 \times 10^{3}$ & $336.8 \times 10^{3}$ & $338.2 \times 10^{3}$ \\
\hline & $\mathrm{n}_{1}$ & $2.8010 \times 10^{-17}$ & $2.8042 \times 10^{-17}$ & $2.8093 \times 10^{-17}$ & $2.8167 \times 10^{-17}$ \\
\hline \multirow[t]{3}{*}{$\mathrm{IIIb}$} & dc-Kerr & $477.5 \times 10^{4}$ & $478.6 \times 10^{4}$ & $480.5 \times 10^{4}$ & $483.0 \times 10^{4}$ \\
\hline & ESHG & $478.3 \times 10^{4}$ & $481.6 \times 10^{4}$ & $487.1 \times 10^{4}$ & $495.1 \times 10^{4}$ \\
\hline & $\mathrm{n}_{1}$ & $4.0144 \times 10^{-16}$ & $4.0325 \times 10^{-16}$ & $4.0630 \times 10^{-16}$ & $4.1064 \times 10^{-16}$ \\
\hline \multirow[t]{3}{*}{ IIIc } & dc-Kerr & $164.2 \times 10^{5}$ & $164.7 \times 10^{5}$ & $165.7 \times 10^{5}$ & $167.0 \times 10^{5}$ \\
\hline & ESHG & $164.6 \times 10^{5}$ & $166.2 \times 10^{5}$ & $169.1 \times 10^{5}$ & $173.3 \times 10^{5}$ \\
\hline & $\mathrm{n}_{1}$ & $1.3962 \times 10^{-15}$ & $1.4055 \times 10^{-15}$ & $1.4211 \times 10^{-15}$ & $1.4435 \times 10^{-15}$ \\
\hline
\end{tabular}


a. $\quad[\mathrm{Ia}=\mathrm{Be} @ \text { aziridine , Ib=Mg@ aziridine, Ic=Ca@ aziridine / Scheme II: IIa=Be@ (aziridine })_{2}$, $\mathrm{IIb}=\mathrm{Mg} @$ (aziridine) $)_{2}, \mathrm{IIc}=\mathrm{Ca} @(\text { aziridine })_{2} /$ Scheme III: IIIa=Be@ (aziridine) $)_{3}$, $\left.\mathrm{IIIb}=\mathrm{Mg} @(\text { aziridine })_{3}, \mathrm{IIIc}=\mathrm{Ca} @(\text { aziridine })_{3}\right]$

Table 8 Transition energy ( $\Delta$ Eng, ev), transition moment $(\mu n g, D)$, dipole moment difference $(\Delta \mu n g, D)$ and oscillator strength (feg) of the complexes ${ }^{\mathrm{a}}$ obtained at the TD-CAMB3LYP level for the 6$311++\mathrm{G}(\mathrm{d}, \mathrm{p})$ basis set

\begin{tabular}{cccccc}
\hline & $\Delta \mathrm{E}_{\mathrm{ng}}$ & $\mathrm{u}_{\mathrm{ng}}^{2}$ & $\Delta \mathrm{u}_{\mathrm{ng}}$ & $\mathrm{fg}$ & Ground $\rightarrow$ Excited states \\
\hline Ia & 4.14 & 2.013 & 2.08 & 0.205 & $\mathrm{~S}_{0} \rightarrow \mathrm{S}_{6}$ \\
Ib & 3.30 & 4.163 & 1.95 & 0.337 & $\mathrm{~S}_{0} \rightarrow \mathrm{S}_{2}$ \\
Ic & 2.29 & 5.516 & 4.09 & 0.310 & $\mathrm{~S}_{0} \rightarrow \mathrm{S}_{2}$ \\
IIa & 3.93 & 1.346 & 0.55 & 0.129 & $\mathrm{~S}_{0} \rightarrow \mathrm{S}_{7}$ \\
IIb & 2.43 & 3.555 & 4.16 & 0.212 & $\mathrm{~S}_{0} \rightarrow \mathrm{S}_{2}$ \\
IIc & 1.88 & 5.339 & 4.82 & 0.247 & $\mathrm{~S}_{0} \rightarrow \mathrm{S}_{3}$ \\
IIIa & 2.69 & 2.676 & 2.01 & 0.177 & $\mathrm{~S}_{0} \rightarrow \mathrm{S}_{2}$ \\
IIIb & 1.70 & 2.943 & 1.89 & 0.122 & $\mathrm{~S}_{0} \rightarrow \mathrm{S}_{2}$ \\
IIIc & 1.13 & 10.522 & 2.93 & 0.292 & $\mathrm{~S}_{0} \rightarrow \mathrm{S}_{1}$ \\
\hline
\end{tabular}

a.[Ia=Be@aziridine, Ib=Mg@aziridine, Ic=Ca@aziridine / Scheme II: Ila=Be@ (aziridine)2, $\mathrm{IIb}=\mathrm{Mg} @(\text { aziridine })_{2}, \mathrm{IIc}=\mathrm{Ca} @(\text { aziridine })_{2} /$ Scheme III: IIIa=Be@ (aziridine $)_{3}$, $\left.\mathrm{IIIb}=\mathrm{Mg} @(\text { aziridine })_{3}, \mathrm{IIIc}=\mathrm{Ca} @(\text { aziridine })_{3}\right]$ 


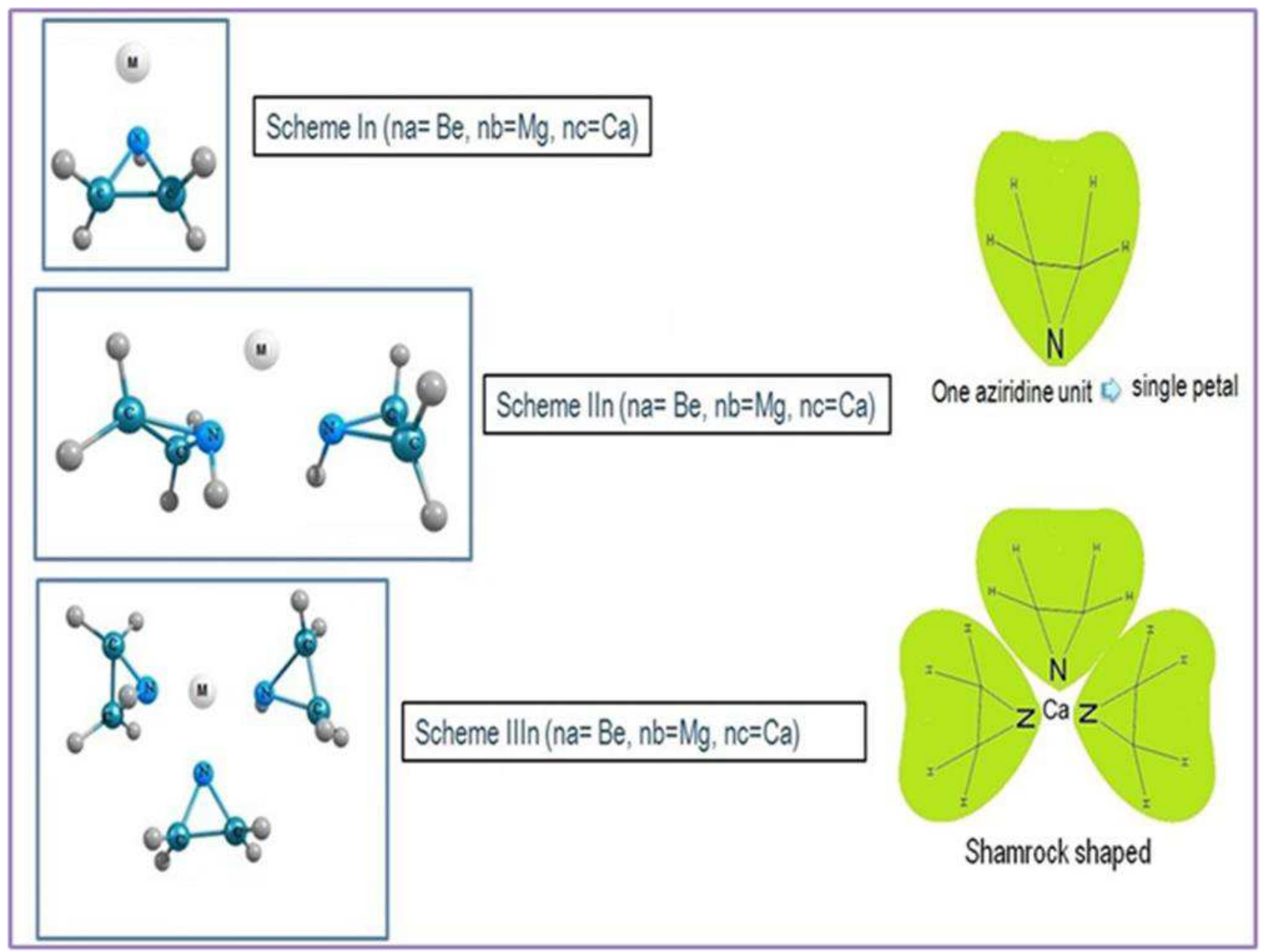

Fig 1. Optimized structure of the complexes of Scheme I-III.[SchemeI: Ia=Be@aziridine , Ib=Mg@aziridine, Ic=Ca@aziridine/SchemeII: IIa=Be@ (aziridine)2, $\mathrm{IIb}=\mathrm{Mg} @(\text { aziridine })_{2}, \mathrm{IIc}=\mathrm{Ca} @(\text { aziridine })_{2} /$ Scheme III:

$\left.\mathrm{IIIa}=\mathrm{Be} @(\text { aziridine })_{3}, \mathrm{IIIb}=\mathrm{Mg} @(\text { aziridine })_{3}, \mathrm{IIIc}=\mathrm{Ca} @(\text { aziridine })_{3}\right]$ 


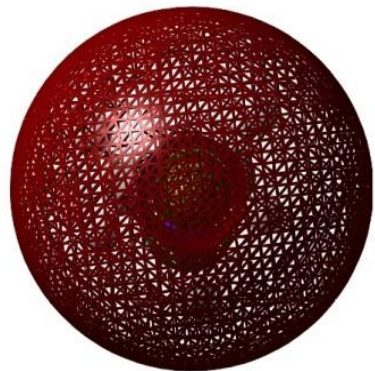

Front-View

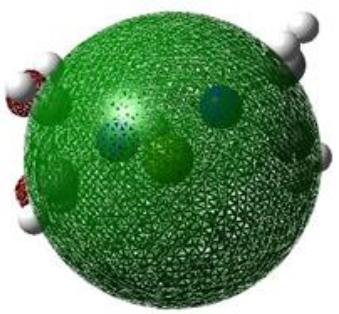

Front-View

Scheme II(IIc)

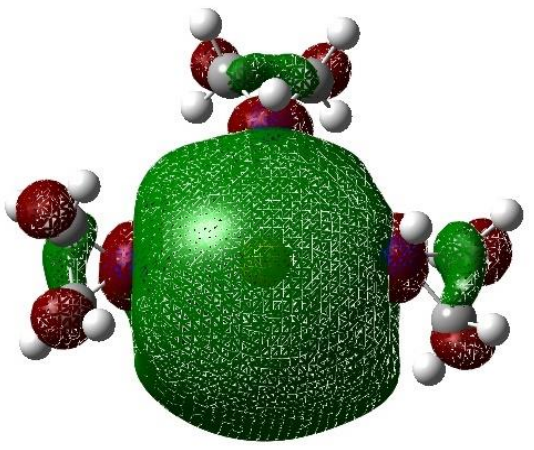

Front-View

Scheme I(Ic)

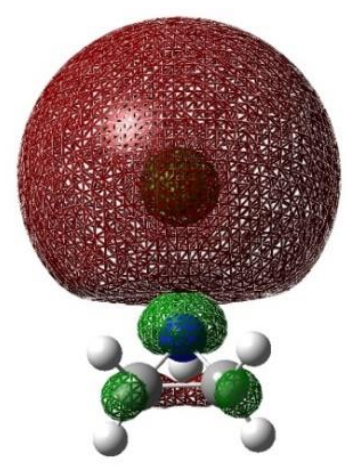

Side -View

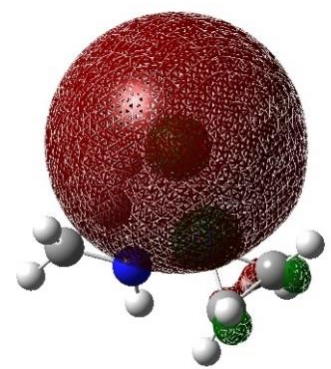

Side-View

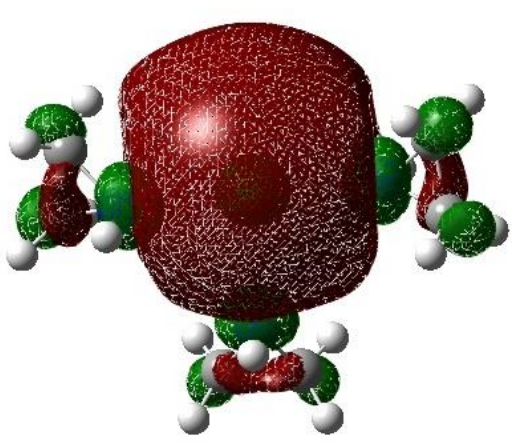

Side-View

\section{Scheme III (IIIc)}

Fig 2. HOMO surface plot (some representative surface plot of the complexes of Scheme I-III)

[Scheme I: , Ic=Ca@ aziridine, Scheme II: IIc=Ca@ (aziridine) $)_{2}$, Scheme III: IIIc=Ca@ (aziridine) ${ }_{3}$ ] 


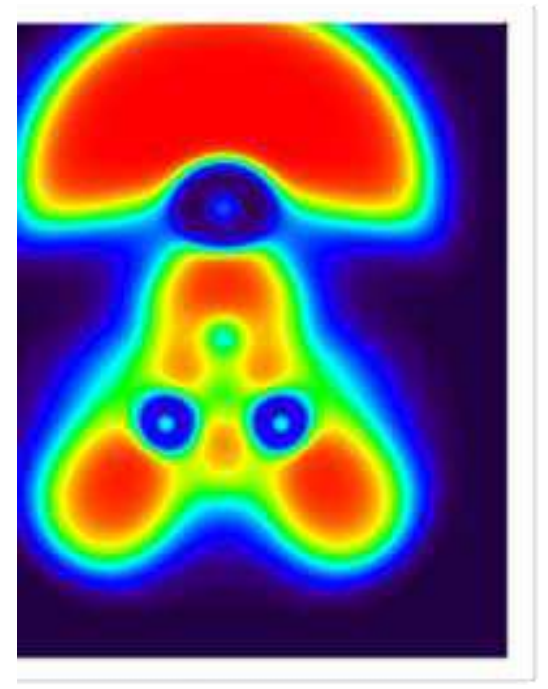

la

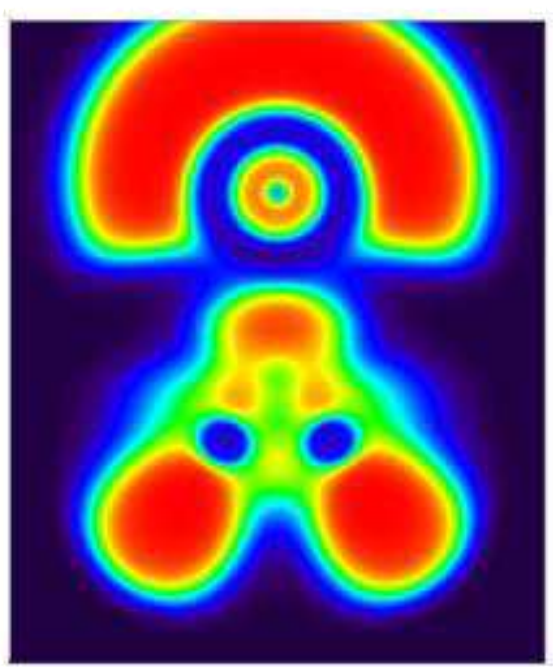

Ib
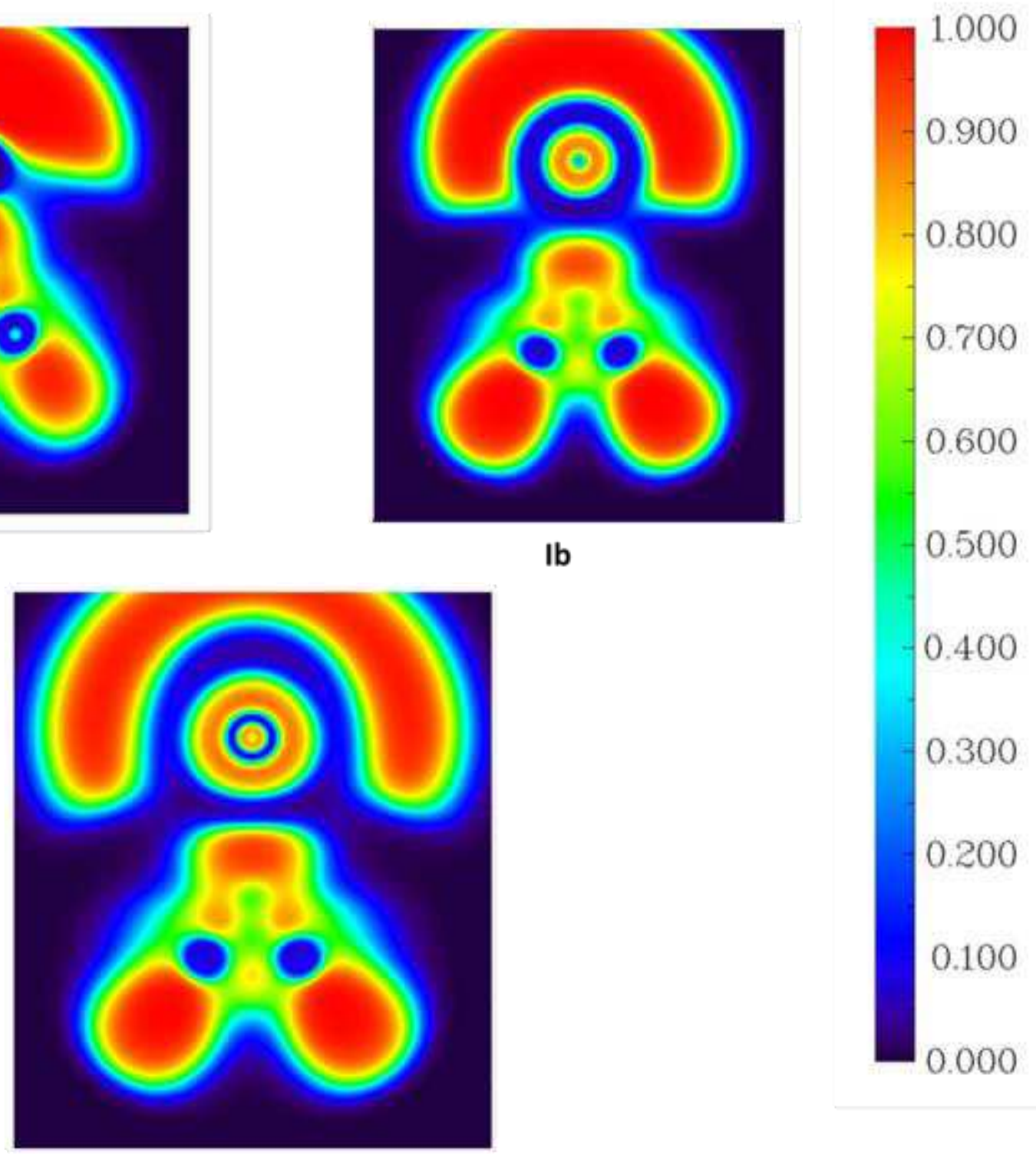

Ic

Fig 3. ELF plot of the complexes of Scheme I

(Scheme I: Ia=Be@ aziridine , Ib=Mg@ aziridine, Ic=Ca@ aziridine) 


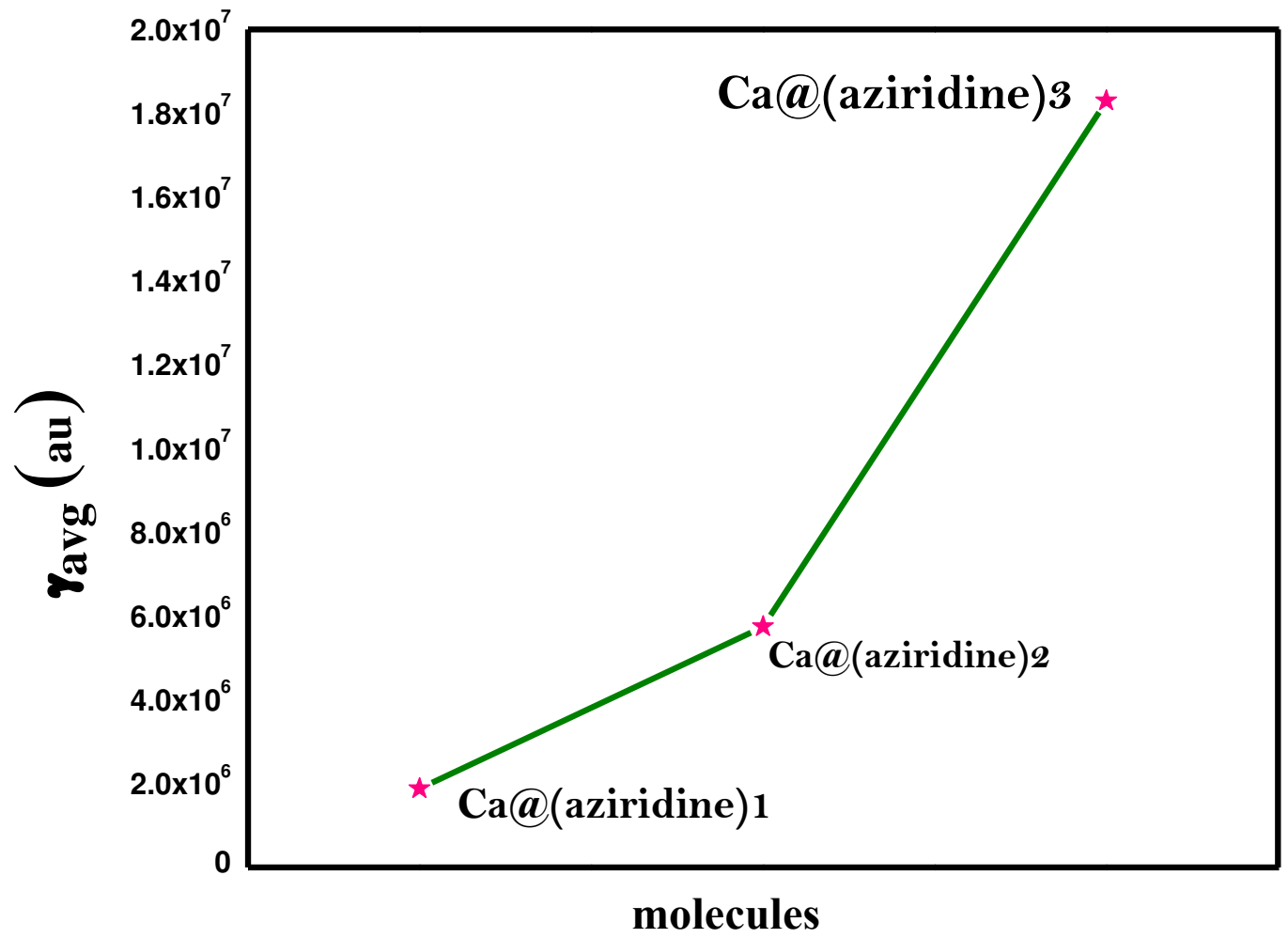

Fig 4. Representative graph showing how the $\gamma_{\text {avincreases with petal number (when } \mathrm{M}=\mathrm{Ca} \text { ) }}$ 


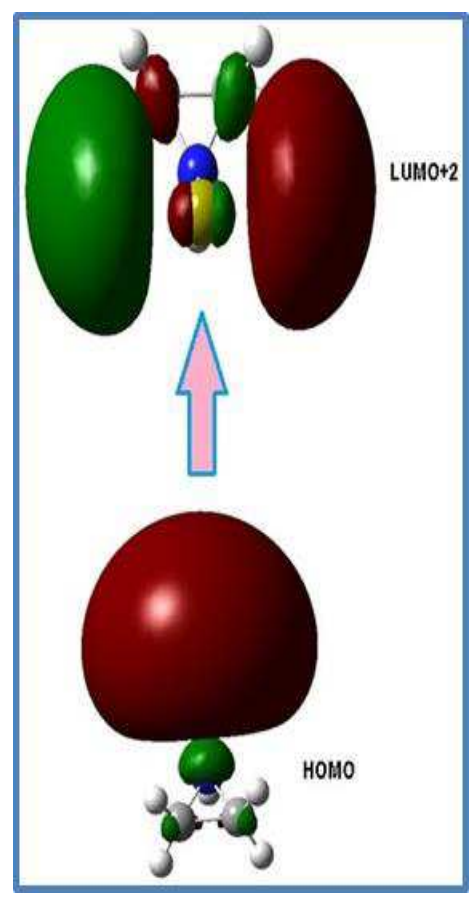

Ic

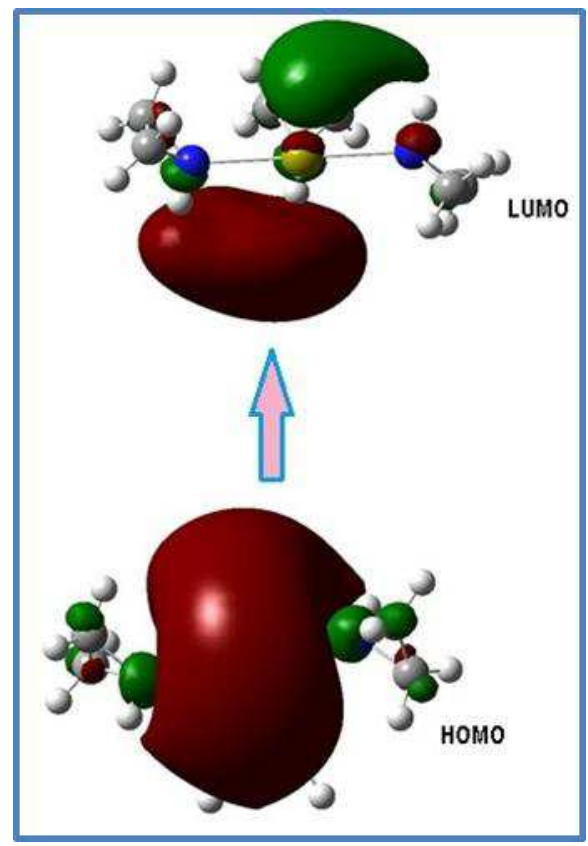

IIIc

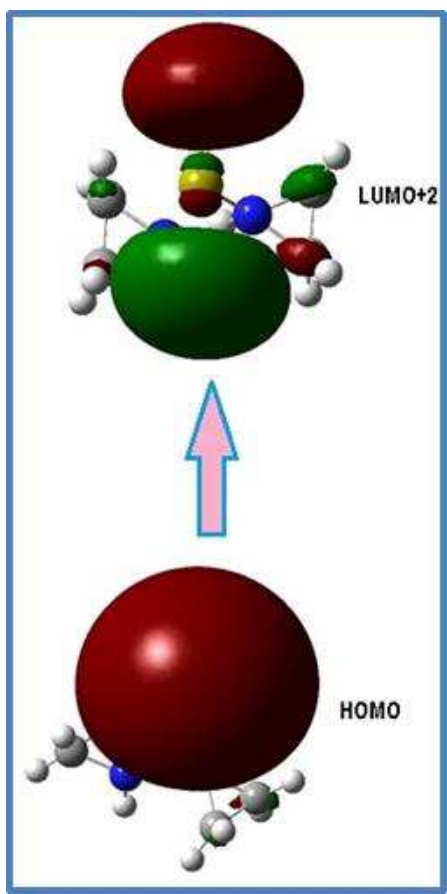

IIc

Fig 5. Frontier molecular orbital diagram of some representative complexes.

Scheme I: , Ic=Ca@ aziridine/ Scheme II: IIc=Ca@ (aziridine) $2 /$ Scheme III: IIIc=Ca@ (aziridine) $)_{3}$ 


\section{Supplementary Files}

This is a list of supplementary files associated with this preprint. Click to download.

- Supplementarysection.docx 